\title{
Comparative Response of the Hepatic Transcriptomes of Domesticated and Wild Turkey to Aflatoxin $\mathbf{B}_{1}$
}

\author{
Kent M. Reed ${ }^{1, *}$ (D) , Kristelle M. Mendoza ${ }^{1}$, Juan E. Abrahante ${ }^{2}$ and Roger A. Coulombe ${ }^{3}$ \\ 1 Department of Veterinary and Biomedical Sciences, College of Veterinary Medicine, University of Minnesota, \\ Saint Paul, MN 55108, USA; mendo008@umn.edu \\ 2 University of Minnesota Informatics Institute, University of Minnesota, Minneapolis, MN 55455, USA; \\ abrah023@umn.edu \\ 3 Department of Animal, Dairy and Veterinary Sciences, College of Agriculture, Utah State University, Logan, \\ UT 84322, USA; roger@usu.edu \\ * Correspondence: reedx054@umn.edu; Tel.: +1-612-624-1287; Fax: +1-612-625-0204
}

Received: 29 November 2017; Accepted: 10 January 2018; Published: 13 January 2018

\begin{abstract}
The food-borne mycotoxin aflatoxin $\mathrm{B}_{1}\left(\mathrm{AFB}_{1}\right)$ poses a significant risk to poultry, which are highly susceptible to its hepatotoxic effects. Domesticated turkeys (Meleagris gallopavo) are especially sensitive, whereas wild turkeys (M. g. silvestris) are more resistant. $\mathrm{AFB}_{1}$ toxicity entails bioactivation by hepatic cytochrome P450s to the electrophilic exo-AFB $1-8,9$-epoxide (AFBO). Domesticated turkeys lack functional hepatic GST-mediated detoxification of AFBO, and this is largely responsible for the differences in resistance between turkey types. This study was designed to characterize transcriptional changes induced in turkey livers by $\mathrm{AFB}_{1}$, and to contrast the response of domesticated (susceptible) and wild (more resistant) birds. Gene expression responses to $\mathrm{AFB}_{1}$ were examined using RNA-sequencing. Statistically significant differences in gene expression were observed among treatment groups and between turkey types. Expression analysis identified 4621 genes with significant differential expression (DE) in $\mathrm{AFB}_{1}$-treated birds compared to controls. Characterization of $\mathrm{DE}$ transcripts revealed genes dis-regulated in response to toxic insult with significant association of Phase I and Phase II genes and others important in cellular regulation, modulation of apoptosis, and inflammatory responses. Constitutive expression of GSTA3 was significantly higher in wild birds and was significantly higher in $\mathrm{AFB}_{1}$-treated birds when compared to controls for both genetic groups. This pattern was also observed by qRT-PCR in other wild and domesticated turkey strains. Results of this study emphasize the differential response of these genetically distinct birds, and identify genes and pathways that are differentially altered in aflatoxicosis.
\end{abstract}

Keywords: aflatoxin $\mathrm{B}_{1}$; domesticated turkey; wild turkey; liver; RNA-seq; differential expression; Results of this study support the hypothesis that the greater ability of wild turkeys to detoxify $\mathrm{AFB}_{1}$ is related to higher constitutive expression of GSTA3 coupled with an inherited (genetic) difference in functional expression in domesticated birds. Key differences in GSTA3 expression between the Eastern wild and domesticated turkeys is not unique to these genetic lines but is a broader phenomenon indicating lower fitness in domesticated birds. Results of RNA-seq analysis emphasize the differential response of these genetically distinct birds, demonstrating significant differences in expression of Phase I and Phase II genes and in genes important in toxic response.

\section{Introduction}

Aflatoxin $\mathrm{B}_{1}\left(\mathrm{AFB}_{1}\right)$ is a ubiquitous hepatotoxic, hepatocarcinogenic, and immunosuppressive mycotoxin. Poultry and other livestock are exposed to $\mathrm{AFB}_{1}$ by consuming contaminated feed. Many agricultural feed commodities (corn, cottonseed, peanuts, and sorghum) and other foods (figs, tree nuts, and spices) are at especially high risk of being contaminated [1]. $\mathrm{AFB}_{1}$ is practically unavoidable 
in most feed ingredients, especially corn [2-4], and is expected to concomitantly increase with global climate change [5]. Approximately 25\% of the world's annual food supply is contaminated with mycotoxins, and losses attributed to $\mathrm{AFB}_{1}$ are significant to the poultry industry [1].

Poultry are among the most sensitive animals to the toxic effects of $\mathrm{AFB}_{1}[6,7]$. Domesticated turkeys are among the most sensitive species [8], but wild turkeys are more resistant [9]. Turkey sensitivity is historically important because it was instrumental in the discovery of $\mathrm{AFB}_{1}$ as being responsible for the deaths of domestic turkeys in Europe due to "Turkey X Disease" that was traced to contaminated feed [10]. $\mathrm{AFB}_{1}$ is a potent immunotoxin acting to suppress cell-mediated, humoral, and phagocytic functions in chickens and turkeys [11-13]. As a result, it has a wide array of toxic effects, including; reduced feed intake, weight gain, and feed efficiency, and increased mortality, hepatotoxicity, GI hemorrhaging, and susceptibility to bacterial and viral diseases. Embryonic exposure to $\mathrm{AFB}_{1}$ produces dose-related DNA damage [14] and compromised immune response through suppression of humoral and cellular immunity making hatched chicks more susceptible to disease [13]. Thus, in addition to being a potent natural toxin, $\mathrm{AFB}_{1}$ is a powerful "force-multiplier", amplifying adverse effects of other agents that are detrimental to poultry health.

Aflatoxin $B_{1}$ toxicity requires bioactivation by hepatic cytochrome P450s (CYPs) to the electrophilic exo-AFB 1 -8,9-epoxide (AFBO). In the absence of GST activity, AFBO can form adducts that bind to DNA, RNA and other macromolecules, causing immunotoxicity, mutations, and aflatoxicosis [15]. The extreme sensitivity of domesticated turkeys to $\mathrm{AFB}_{1}$ is associated with efficient epoxidation by cytochromes P4501A5 and 3A37 [16], both of which have been cloned, heterologously expressed and functionally characterized [8,17]. Using anti-peptide antibodies, P4501A5 was found to be the dominant bioactivating and metabolizing enzyme at environmentally relevant $\mathrm{AFB}_{1}$ concentrations in turkey liver [8].

While P450-mediated bioactivation plays an important role, the principal determinant of response to $\mathrm{AFB}_{1}$ is the efficiency of detoxification by hepatic glutathione S-transferases (GSTs), most notably alpha class (GSTAs) [18]. The $\alpha$-GST cluster in turkeys includes six genes, GSTA1.1-A1.3, GSTA2, GSTA3, and GSTA4 [19,20]. Whereas, wild and heritage breed turkeys possess GST-mediated AFBO detoxification activity, livers from domestic turkeys lack detectable activity [20]. Thus, the most likely mechanism for the extreme sensitivity of domestic turkeys is dysfunction in hepatic GSTs, rendering them unable to detoxify $\mathrm{AFB}_{1}$ [21-23]. As a result, $\mathrm{AFBO}$ forms adducts, which can induce DNA mutations, block transcription and alter translation [24,25].

To understand the response of the domesticated turkey to $\mathrm{AFB}_{1}$ exposure, we initiated study of the hepatic transcriptome following dietary $\mathrm{AFB}_{1}$ challenge. Results of this study identified genes and gene pathways in the liver directly affected by $\mathrm{AFB}_{1}$ [26]. Functional analysis found transcripts significantly dis-regulated by toxicity and affecting pathways of cancer, apoptosis, cell cycle, and lipid regulation. These changes reflect the molecular mechanisms of inflammation, proliferation and liver damage in aflatoxicosis. This study was followed by analysis of spleen tissues from the same birds [27] that found short exposure to $\mathrm{AFB}_{1}$ suppressed innate immune transcripts, especially from antimicrobial genes that are indicative of either increased cytotoxic potential or activation-induced cell death in the spleen during aflatoxicosis.

To better examine the differences between wild and domesticated birds, we developed an in ovo exposure model to provide controlled $\mathrm{AFB}_{1}$ exposure to developing embryos [28]. RNA-seq analysis found $\mathrm{AFB}_{1}$ effects were dependent on both length of exposure and turkey type (domesticated vs. wild), confirming significant differences in the response to $\mathrm{AFB}_{1}$ attributed to genetic background [28]. Transcriptome responses to $\mathrm{AFB}_{1}$ occurred more rapidly in domesticated birds (1 day post-exposure), and led to the up regulation in cell cycle regulators, Nrf2-mediated response genes and coagulation factors. Expression changes in the embryonic liver also suggested cellular responses to oxidative stress and xenobiotics were initiated by $\mathrm{AFB}_{1}$ exposure. In contrast, the response in wild turkey embryos occurred later (five days post-exposure). Combined, these studies demonstrated that GST-mediated hepatic detoxification of AFBO is largely responsible for the differences in resistance between turkey 
types, but other processes and pathways (i.e., apoptosis, cellular regulation, immune responses) are also important. Whereas, understanding the effects of $\mathrm{AFB}_{1}$ on developing embryos is important in poultry production, the manifestation of $\mathrm{AFB}_{1}$ toxicity is likely to be different in more mature birds with fully developed gastrointestinal systems. The purpose of this study was to compare the hepatic transcriptome response to dietary $\mathrm{AFB}_{1}$ in juvenile (three weeks of age), susceptible (domesticated), and more resistant (wild) turkeys. We hypothesized that transcriptome responses in juvenile birds would reflect the more mature status of the gastrointestinal and antioxidant systems than those of embryos.

\section{Results}

Liver measurements were collected at the end of the exposure trial to characterize phenotypic effects of $\mathrm{AFB}_{1}$ toxicity. Livers of domesticated (DT) birds (average $=20.54 \mathrm{~g}$ ) were nearly three times the mass of those from Eastern wild (EW) birds $(8.3 \mathrm{~g})$ primarily due to differences in body size (average $=1147.5 \mathrm{~g}$ and $396.1 \mathrm{~g}$, respectively). Liver weights of $\mathrm{AFB}_{1}$ turkeys were smaller than those of the control (CNTL) groups. In DT, average liver mass at the conclusion of the trial ranged from $14.76 \mathrm{~g}$ to $23.98 \mathrm{~g}$ in the $\mathrm{AFB}_{1}$ group (mean = $20.02 \pm 2.44 \mathrm{~g}$ ) and from $17.39 \mathrm{~g}$ to $25.11 \mathrm{~g}$ in controls $(21.00 \pm 2.12 \mathrm{~g})$. Although this difference in liver mass was not significant $(t$-test $p=0.1962)$, when corrected for body weight (\% BW) the livers of birds from the $\mathrm{AFB}_{1}$-treated group were significantly smaller $(p=0.0098)$. Livers of $\mathrm{AFB}_{1}$-treated EW birds $(7.19 \pm 1.06 \mathrm{~g})$ were similarly smaller than those of control birds $(9.43 \pm 1.11 \mathrm{~g})$. This difference was significant for absolute mass $(p=0.0005)$ and nearly so for $\%$ BW $(p=0.0531)$.

Sequencing of RNA libraries produced over $195 \mathrm{M}$ reads. The number of reads per library ranged from 10.8 M to 14.6 M (average 12.2 M, Table 1). After trimming and filtering, median Q scores were consistently high and ranged from 36.4 to 37.4 among the forward and reverse reads. The number of reads per treatment group was balanced and ranged from 11.5 to $12.7 \mathrm{M}$, with an average of $12.21 \pm 0.5 \mathrm{M}$. Approximately $91 \%$ of the quality-trimmed reads mapped to the annotated turkey gene set (NCBI Annotation 101, Table 1). This percentage was consistent across treatment groups and the percentage of aligned read pairs exceeded $89.7 \%$ (average $=90.8 \%$ ); the majority of reads (average $=85.3 \%$ ) mapped concordantly (Table 1). Based on mapping, the estimated mean library insert was $191.7 \mathrm{bp}$.

Principal component analysis (PCA) of normalized read counts visualized variation among the treatment groups (Figure 1). Groups clustered distinctly according to treatment ( $\mathrm{AFB}_{1}$ versus control) within the first two principal components, accounting for approximately $95 \%$ of the observed variation. Hierarchical clustering of groups by Euclidean distance reiterated the relationships shown by PCA (Figure S1). After segregating by $\mathrm{AFB}_{1}$ treatment, groups secondarily cluster by type (domesticated versus wild), with the exception of samples N3L (domesticated) and EW1L (wild) that clustered with the opposite bird type. Significant differences in overall gene counts among groups are shown in the heat map of co-expressed genes. 
Table 1. Summary of RNA-seq data for turkey liver transcriptomes.

\begin{tabular}{|c|c|c|c|c|c|c|c|c|c|c|c|}
\hline Line & Group & Replicate & PE Reads & $\begin{array}{c}\text { Median Read } \\
\text { Quality R1 }\end{array}$ & $\begin{array}{c}\text { Median Read } \\
\text { Quality R2 }\end{array}$ & \% Mapped & $\%$ Concordant & $\begin{array}{l}\text { Estimated Insert } \\
\text { Mean (bp) }\end{array}$ & $\begin{array}{l}\text { Observed } \\
\text { Genes }\end{array}$ & $\begin{array}{l}\text { Expressed } \\
\text { Genes }\end{array}$ & $\begin{array}{c}\text { \% Genes } \\
\text { Expressed }\end{array}$ \\
\hline \multirow[t]{10}{*}{ Eastern Wild } & CNTL & EW9L & $12,148,654$ & 36.5 & 36.6 & 91.7 & 86.8 & 172 & 15,857 & 14,804 & 70.5 \\
\hline & & EW10L & $14,641,781$ & 36.4 & 36.5 & 90.9 & 85.7 & 173 & 16,483 & 14,833 & 70.6 \\
\hline & & EW12L & $11,740,806$ & 36.9 & 36.8 & 91.1 & 85.8 & 191 & 16,506 & 15,448 & 73.5 \\
\hline & & EW13L & $12,466,171$ & 36.9 & 36.9 & 90.9 & 85.4 & 191 & 16,572 & 14,935 & 71.1 \\
\hline & & Mean & $12,749,353.0$ & 36.68 & 36.70 & 91.15 & 85.93 & 181.8 & $16,354.5$ & $15,005.0$ & 71.4 \\
\hline & AFB & EW1L & $11,719,049$ & 36.9 & 37.0 & 89.7 & 83.6 & 192 & 17,914 & 17,073 & 81.3 \\
\hline & & EW2L & $12,615,195$ & 36.9 & 37.0 & 90.1 & 84.2 & 191 & 17,911 & 16,523 & 78.6 \\
\hline & & EW3L & $12,625,962$ & 36.9 & 36.9 & 90.5 & 84.7 & 192 & 18,026 & 17,194 & 81.8 \\
\hline & & EW4L & $12,468,136$ & 36.9 & 36.9 & 89.9 & 84.0 & 193 & 18,054 & 17,230 & 82.0 \\
\hline & & Mean & $12,357,085.5$ & 36.90 & 36.95 & 90.05 & 84.13 & 192.0 & $17,976.3$ & $17,005.0$ & 80.9 \\
\hline \multirow[t]{10}{*}{ Domesticated } & CNTL & N11L & $12,448,496$ & 36.7 & 36.8 & 92.4 & 87.7 & 172 & 15,993 & 14,837 & 70.6 \\
\hline & & N12L & $12,857,795$ & 36.7 & 36.7 & 92.3 & 87.7 & 172 & 16,136 & 14,399 & 68.5 \\
\hline & & N13L & $11,417,338$ & 37.2 & 37.4 & 91.4 & 85.7 & 212 & 16,634 & 15,584 & 74.2 \\
\hline & & N14L & $12,099,335$ & 36.7 & 36.6 & 91.9 & 87.0 & 170 & 15,952 & 14,780 & 70.4 \\
\hline & & Mean & $12,205,741.0$ & 36.83 & 36.88 & 92.00 & 87.03 & 181.5 & $16,178.7$ & $14,900.0$ & 70.9 \\
\hline & AFB & N1L & $11,388,753$ & 37.2 & 37.4 & 90.3 & 84.3 & 212 & 17,967 & 17,109 & 81.4 \\
\hline & & N2L & $12,827,964$ & 37.1 & 37.3 & 89.8 & 83.6 & 213 & 18,083 & 16,752 & 79.7 \\
\hline & & N3L & $10,821,683$ & 37.1 & 37.3 & 90.4 & 84.4 & 211 & 17,903 & 17,048 & 81.1 \\
\hline & & $\mathrm{N} 4 \mathrm{~L}$ & $11,144,371$ & 37.2 & 37.3 & 90.1 & 84.0 & 211 & 17,989 & 17,119 & 81.5 \\
\hline & & Mean & $11,545,693.0$ & 37.15 & 37.33 & 90.15 & 84.08 & 211.8 & $17,985.5$ & $17,007.0$ & 81.0 \\
\hline Mean & & & $12,214,468.06$ & 36.89 & 36.96 & 90.84 & 85.29 & 191.75 & $17,123.75$ & $15,979.25$ & 76.1 \\
\hline
\end{tabular}

For each library the total number of concatenated reads, median read qualities (R1 and R2), estimated mean insert length (bp), number of and percentage of aligned reads, percentage of concordant reads, and the number and percentage of observed genes (mapped reads > 1) and expressed genes (mean group normalized read count $>3.0$ ) are given. 


\subsection{Gene Expression}

Evidence of expression (mean mapped reads $\geq 1.0$ in at least one treatment group) was detected for 19,764 genes (tRNAs excluded), with an average of 17,137.5 genes being detected per group (81.56\% of the turkey gene set) (Table S1). Mean read depth was 394.8 reads per gene. When limited to an average number of mapped reads $\geq 3.0$, the number of expressed genes ranged from 14,399 to 17,230 among treatment groups (average 15,979.25, Table 1). Distribution of unique and shared expressed genes is illustrated in Figure S2. A total of 14,373 genes (81.2\%) was co-expressed among all groups, and the number of co-expressed genes within the EW and DT lines was 14,908 and 14,669, respectively. Each treatment group had distinct sets of uniquely expressed genes, but that number was considerably greater in the $\mathrm{AFB}_{1}$-treatment groups $(2169,12.3 \%)$ when compared to controls $(300,1.6 \%$, Table 1 and Table S1).

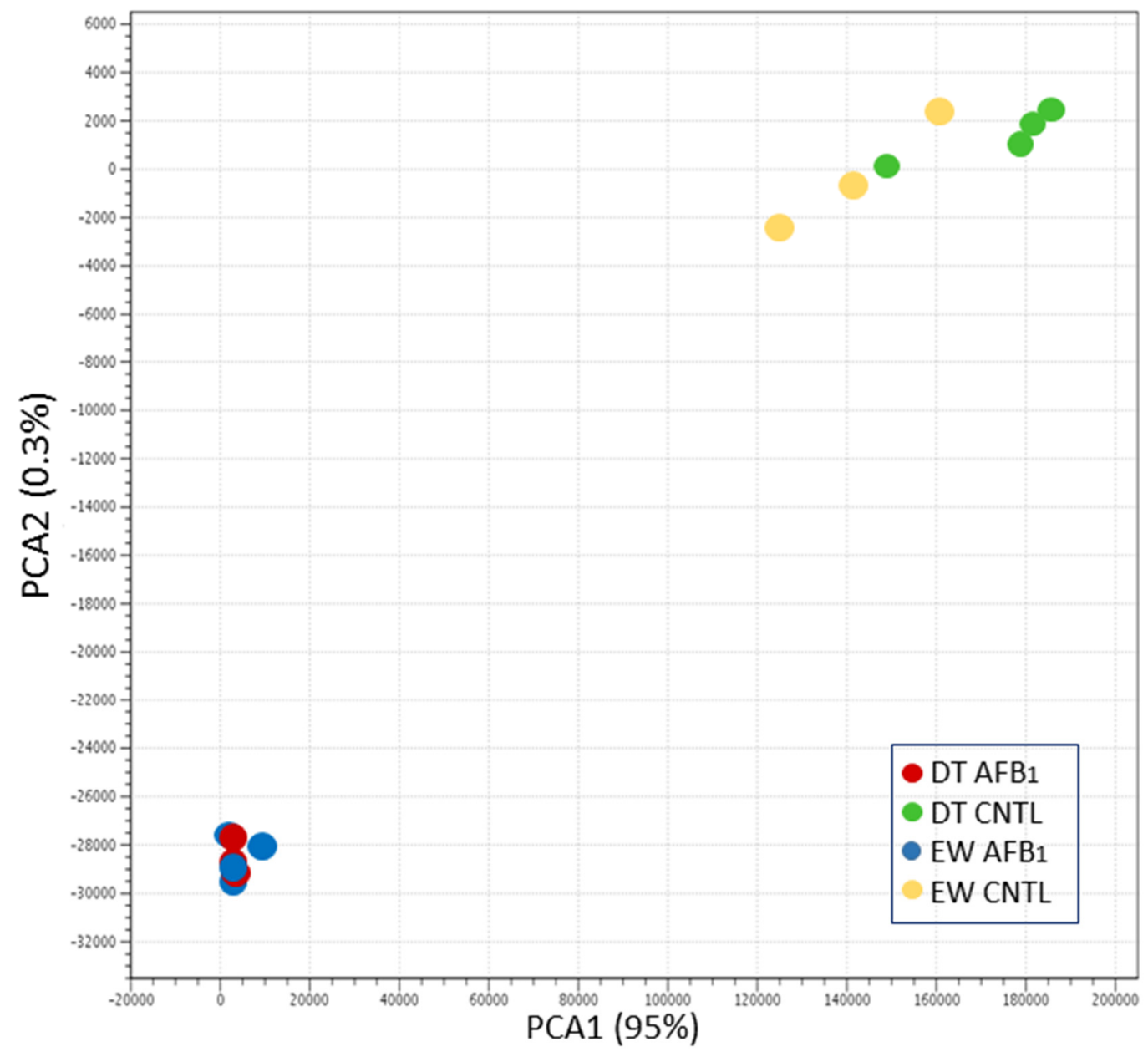

Figure 1. Principal component analysis (PCA) of normalized RNA-seq read counts. For each treatment group, sample to sample distances (within- and between-treatments) are illustrated on the first two principal components comprising approximately $95 \%$ of the variation.

\subsection{Differential Transcriptomic Expression: $A F B_{1}$ Effects}

Table S2 provides the full list of genes showing significant differential expression (DE). DE was observed for 9620 genes (FDR $p$-value $<0.05, \log _{2} \mathrm{FC}=-9.670$ to 9.358 ) in wild turkeys exposed to $\mathrm{AFB}_{1}$ when compared to control birds with 4176 genes having $\mid \log _{2} \mathrm{FCl}>2.0$ (Table 2). Similarly, 11,325 DE genes were observed for the $\mathrm{AFB}_{1}$-treated DT turkeys (FDR $p$-value $<0.05, \log _{2} \mathrm{FC}=$ -14.133 to 12.676 ) with 4621 genes having $\mid \log _{2} \mathrm{FCl}>2.0$. The majority of DE genes (3380) were 
shared in both bird types, with 796 being unique to wild and 1241 unique to the domesticated birds (Figure 2). The majority of DE genes was up regulated by $\mathrm{AFB}_{1}$ treatment in both the wild (2717, $65 \%)$ and domesticated birds (2914,70\%). Of the 50 genes showing the greatest fold change with treatment, seven (ANGPTL3 [angiopoietin-like 3], GC [group-specific component (vitamin D binding protein)], LOC104911607 [uncharacterized ncRNA], LOC100541166 [alpha-1-acid glycoprotein 2-like], LOC100542070 [SERPINA1-like, alpha-1-antitrypsin-like], NME4 [NME/NM23 nucleoside diphosphate kinase 4], and TAT [tyrosine aminotransferase]) were shared between the bird types (Table S3). In mammals, ANGPTL3 is in part involved in regulation of lipid and glucose metabolism by inhibiting the lipolysis of triglyceride-rich lipoproteins [29,30]. This transcript was highly down regulated in the $\mathrm{AFB}_{1}$-treated turkeys ( $\log _{2} \mathrm{FC}=-7.94$ and -14.13 in EW and DT, respectively). Similarly down regulated was GC an important protein in vitamin D transport and storage, actin-scavenging, and enhancement of complement component 5 a activity for neutrophils in inflammation and during macrophage activation [31]. Comparison analysis in IPA found the most significant canonical pathways to include "Axonal Guidance Signaling" and "Hepatic Fibrosis/Stellate Cell activation". Hepatic stellate cells are closely linked to the progression of hepatic fibrosis [32].

Table 2. Summary of genes with significant differential expression (DE) in pair-wise comparisons of treatment groups.

\begin{tabular}{cccccccc}
\hline \multirow{2}{*}{ Comparison } & Groups & $\begin{array}{c}\text { Expressed } \\
\text { Genes }\end{array}$ & $\begin{array}{c}\text { Shared } \\
\text { Genes }\end{array}$ & $\begin{array}{c}\text { Unique } \\
\text { Genes/Group }\end{array}$ & $\begin{array}{c}\text { FDR Pval } \\
<\mathbf{0 . 0 5}\end{array}$ & $\begin{array}{c}\mid \log _{2} \mathrm{FCl} \\
\mathbf{>} \mathbf{1 . 0}\end{array}$ & $\begin{array}{c}\mid \mathbf{l o g}_{\mathbf{2}} \mathrm{FCl} \\
\mathbf{2} \mathbf{2 . 0}\end{array}$ \\
\hline \multirow{2}{*}{$\mathrm{AFB}_{1}$ effect } & EW (AFB vs. CNTL) & 17,342 & 14,908 & $2147 / 287$ & 9620 & 7168 \\
& DT (AFB vs. CNTL) & 17,403 & 14,669 & $2407 / 328$ & 11,325 & 8001 & 4621 \\
\hline \multirow{2}{*}{ Line } & CNTL (EW vs. DT) & 15,525 & 14,667 & $528 / 330$ & 744 & 495 & 184 \\
& AFB (EW vs. DT) & 17,411 & 16,719 & $336 / 356$ & 903 & 456 \\
\hline
\end{tabular}

For each comparison, the treatment groups, number of genes with significant FDR $p$-value, and the numbers of significant genes that also had $\mid \log _{2}$ fold change $\mid>1.0$ and $>2.0$ are given.

\section{AFB1 vs CNTL}

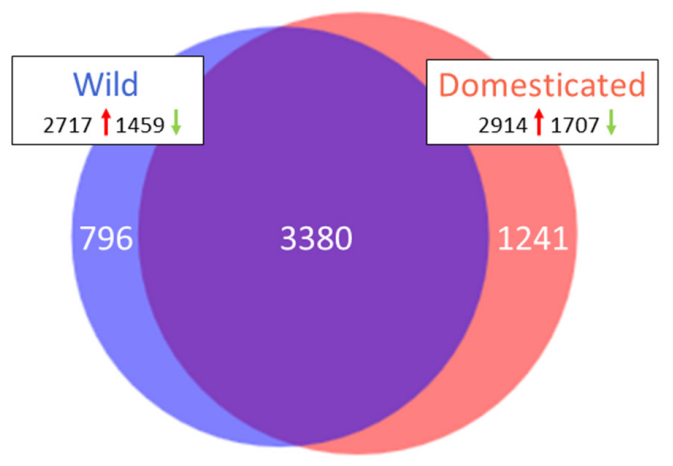

Figure 2. Distribution of differentially expressed genes in turkey. For each comparison, the number of genes with FDR $p$-value $<0.05$ and $\mid \log _{2} \mathrm{FCl}>2.0$ shared or unique to each treatment are indicated in the Venn diagram. Circle size is proportional to the number of genes and direction of expression change ( $\uparrow$ or $\downarrow$ ) is given for the genes in each group.

\subsubsection{Shared DE Genes}

Changes in expression of the 3380 shared significant DE genes were highly correlated $\left(\mathrm{r}^{2}=0.909\right.$, $\mathrm{F}=0.010$, Figure S1) and essentially linear, except for genes with the greatest down regulation where $\log _{2} \mathrm{FC}$ in the domestic birds tended to be of greater magnitude than observed for the wild birds. This is consistent with a common physiological response to $\mathrm{AFB}_{1}$ exposure. Of the 3380 shared DE genes, 1609 IDs mapped to the G. gallus gene REFLIST and statistical overrepresentation tests (PANTHER) of these shared DE genes found the greatest enrichment in the Biological Process 
category for "amino acid processes" and "negative regulators of hemostasis and wound healing" (Table S4). Comparison analysis in IPA found the most significant toxicology functions consistent with cellular damage. Categories with the greatest number of included genes included "liver hyperplasia/hyperproliferation" $\left(p=5.10 \times 10^{-41}\right)$, "cardiac hypertrophy" $\left(p=2.91 \times 10^{-12}\right)$, "renal necrosis/cell death" $\left(p=7.78 \times 10^{-12}\right)$, and "liver steatosis" $\left(p=1.75 \times 10^{-11}\right)$. Highest activation $(\mathrm{Z})$ scores were obtained for "Integrin Signaling", "Rho Family GTPase signaling", and "NFAT regulation of immune response" pathways.

Only two loci among the 3380 shared significant DE genes showed opposite directional expression changes between wild and domesticated birds. CD96, a T cell-specific receptor, was significantly up regulated in response to $\mathrm{AFB}_{1}$ in the EW birds $\left(\log _{2} \mathrm{FC}=3.83\right)$ but down regulated in $\mathrm{DT}\left(\log _{2} \mathrm{FC}=-2.15\right)$. CD96 may play a role in the adhesive interactions of activated T and NK cells when actively engaging diseased cells within areas of inflammation [33]. A second locus (LOC104911020, serum amyloid A protein-like) was significantly down regulated in response to $\mathrm{AFB}_{1}$ in $\mathrm{EW}$ birds $\left(\log _{2} \mathrm{FC}=-3.99\right)$, but up regulated in DT $\left(\log _{2} \mathrm{FC}=2.22\right)$. Serum amyloid A $(\mathrm{SAA})$ proteins are a family of apolipoproteins produced primarily by the liver and are associated with high-density lipoprotein in plasma [34].

\subsubsection{Unique Responses}

Although the greatest number of DEGs was shared between the domesticated and wild turkey comparisons, 796 DEGs were uniquely affected in the wild birds exposed to $\mathrm{AFB}_{1}$ in comparison to their controls (Figure 2). Up-regulated genes with the greatest fold change in the EW birds (Table S3) included several transcription factors (DMRT2, FOXF2, HOXD10, HOXA9, HOXD8) and transporters (LOC100548321 [pendrin], SLC13A1, SLC6A18). DEGs with the greatest negative fold change (down regulated) include the cytochrome P450s (LOC100548279 [CYP2K4-like], LOC100546803 [CYP8B1], and LOC100539035 [CYP7A1]), metabolic inhibitors (LOC100542224 [alpha-1-antitrypsin-like], INHBC [inhibin, beta C], LOC104912821 [ovostatin homolog], LOC104915655 [alpha-2-macroglobulin-like]), and several ncRNAs. Of the 796 unique DEGs in the EW comparison, 336 had mapped IDs in G. gallus REFLIST and overrepresentation tests in PANTHER found greatest enrichment in the Biological Process category were genes in the GO classifications of "negative regulation of neurogenesis" (GO:0050768) and "negative regulation of cell development" (GO:0010721) with 5.58- and 5.13-fold enrichment, respectively (Table 3). Effected Cellular Component groups included "elements of the sarcolemma" (GO:0042383) and "proteinaceous extracellular matrix" (GO:0005578) enriched by 7.65- and 3.92-fold, respectively.

A greater number of DEGs (1241) were uniquely affected in the domesticated birds exposed to $\mathrm{AFB}_{1}$, in comparison to their controls. Of the $50 \mathrm{DEGs}$ with the greatest fold change in the domesticated birds, only two were up regulated; SMIM24 (small integral membrane protein 24) and LOC100546964 (cis-aconitate decarboxylase-like) (Table S3). The function of SMIM24 is currently unknown. In humans, cis-aconitate decarboxylase $(A C O D 1=I R G 1)$ is highly expressed in mammalian macrophages during inflammation where it catalyzes itaconic acid production [35]. Among the most down-regulated loci in DT were ANGPTL3 (angiopoietin-like 3) which in humans, is expressed predominantly in the liver and functions in angiogenesis, and Fibrinogen $(F G A, F G B$, and $F G G)$ and other coagulation components like coagulation factor IX (F9). This set of down-regulated DEGs also included LOC100547030 (a cytochrome P450 2W1-like gene). In humans, CYP2W1 is able to metabolically activate several pro-carcinogens, including $\mathrm{AFB}_{1}$, into cytotoxic products [36]. Due to its selective expression, $C Y P 2 \mathrm{~W} 1$ is suggested as a potential prognostic biomarker in hepatocellular and other carcinomas [37].

GO analysis of the DEGs unique to the domestic turkey liver indicate a number of distinctive responses to $\mathrm{AFB}_{1}$. Of the 1241 DEGs, 636 mapped to IDs in G. gallus REFLIST and overrepresentation tests in PANTHER found the greatest enrichment for biological process categories "organelle fission" (GO:0048285), "oxidation-reduction process" (GO:0055114), and "regulation of immune system process" (GO:0002682) (Table 4). Cellular component categories were enriched for mitochondrial and membrane components. 
Table 3. Summary of PANTHER Overrepresentation Test of the 796 unique differentially expressed (DE) genes in livers of Eastern wild turkeys compared to controls after $\mathrm{AFB}_{1}$ exposure.

\begin{tabular}{|c|c|c|c|c|c|c|}
\hline Category & $\begin{array}{c}\text { Gallus gallus-REFLIST } \\
\text { Genes }(15,789)\end{array}$ & $\begin{array}{c}\text { Observed Turkey } \\
\text { Genes }\end{array}$ & Expected & over/under & Fold Enrichment & $p$-Value \\
\hline \multicolumn{7}{|l|}{ GO biological process complete } \\
\hline negative regulation of neurogenesis (GO:0050768) & 101 & 12 & 2.15 & + & 5.58 & $1.28 \times 10^{-2}$ \\
\hline negative regulation of cell development (GO:0010721) & 119 & 13 & 2.53 & + & 5.13 & $1.21 \times 10^{-2}$ \\
\hline negative regulation of nervous system development (GO:0051961) & 111 & 12 & 2.36 & + & 5.08 & $3.29 \times 10^{-2}$ \\
\hline regulation of system process (GO:0044057) & 184 & 16 & 3.92 & + & 4.09 & $1.58 \times 10^{-2}$ \\
\hline regulation of membrane potential (GO:0042391) & 185 & 16 & 3.94 & + & 4.06 & $1.69 \times 10^{-2}$ \\
\hline regulation of neuron differentiation (GO:0045664) & 233 & 19 & 4.96 & + & 3.83 & $4.83 \times 10^{-3}$ \\
\hline regulation of neurogenesis (GO:0050767) & 279 & 20 & 5.94 & + & 3.37 & $1.72 \times 10^{-2}$ \\
\hline neurological system process (GO:0050877) & 337 & 22 & 7.17 & + & 3.07 & $2.45 \times 10^{-2}$ \\
\hline system process (GO:0003008) & 559 & 30 & 11.9 & + & 2.52 & $2.36 \times 10^{-2}$ \\
\hline generation of neurons (GO:0048699) & 589 & 31 & 12.53 & + & 2.47 & $2.40 \times 10^{-2}$ \\
\hline neurogenesis (GO:0022008) & 636 & 33 & 13.53 & + & 2.44 & $1.57 \times 10^{-2}$ \\
\hline nervous system development (GO:0007399) & 886 & 44 & 18.85 & + & 2.33 & $1.03 \times 10^{-3}$ \\
\hline regulation of multicellular organismal process (GO:0051239) & 1083 & 52 & 23.05 & + & 2.26 & $2.01 \times 10^{-4}$ \\
\hline system development (GO:0048731) & 1613 & 64 & 34.33 & + & 1.86 & $4.44 \times 10^{-3}$ \\
\hline cell communication (GO:0007154) & 2250 & 85 & 47.88 & + & 1.78 & $3.50 \times 10^{-4}$ \\
\hline single organism signaling (GO:0044700) & 2201 & 83 & 46.84 & + & 1.77 & $5.71 \times 10^{-4}$ \\
\hline multicellular organismal process (GO:0032501) & 2417 & 91 & 51.44 & + & 1.77 & $1.16 \times 10^{-4}$ \\
\hline multicellular organism development (GO:0007275) & 1814 & 68 & 38.6 & + & 1.76 & $1.37 \times 10^{-2}$ \\
\hline single-multicellular organism process (GO:0044707) & 2120 & 79 & 45.11 & + & 1.75 & $2.09 \times 10^{-3}$ \\
\hline anatomical structure development (GO:0048856) & 1971 & 71 & 41.94 & + & 1.69 & $3.16 \times 10^{-2}$ \\
\hline single-organism process (GO:0044699) & 6098 & 180 & 129.77 & + & 1.39 & $1.05 \times 10^{-4}$ \\
\hline Unclassified (UNCLASSIFIED) & 6357 & 84 & 135.28 & - & 0.62 & $0.00 \times 10$ \\
\hline
\end{tabular}


Table 3. Cont

\begin{tabular}{|c|c|c|c|c|c|c|}
\hline Category & $\begin{array}{c}\text { Gallus gallus-REFLIST } \\
\text { Genes }(15,789)\end{array}$ & $\begin{array}{l}\text { Observed Turkey } \\
\text { Genes }\end{array}$ & Expected & over/under & Fold Enrichment & $p$-Value \\
\hline \multicolumn{7}{|l|}{ GO cellular component complete } \\
\hline sarcolemma (GO:0042383) & 43 & 7 & 0.92 & + & 7.65 & $4.23 \times 10^{-2}$ \\
\hline proteinaceous extracellular matrix (GO:0005578) & 168 & 14 & 3.58 & + & 3.92 & $1.85 \times 10^{-2}$ \\
\hline extracellular matrix (GO:0031012) & 249 & 18 & 5.3 & + & 3.4 & $8.51 \times 10^{-3}$ \\
\hline plasma membrane part (GO:0044459) & 987 & 45 & 21.0 & + & 2.14 & $1.33 \times 10^{-3}$ \\
\hline intrinsic component of membrane (GO:0031224) & 3244 & 132 & 69.03 & + & 1.91 & $3.19 \times 10^{-12}$ \\
\hline integral component of membrane (GO:0016021) & 3200 & 129 & 68.1 & + & 1.89 & $1.70 \times 10^{-11}$ \\
\hline plasma membrane (GO:0005886) & 1834 & 71 & 39.03 & + & 1.82 & $4.27 \times 10^{-4}$ \\
\hline membrane part (GO:0044425) & 3689 & 142 & 78.5 & + & 1.81 & $1.39 \times 10^{-11}$ \\
\hline cell periphery (GO:0071944) & 1888 & 72 & 40.18 & + & 1.79 & $6.08 \times 10^{-4}$ \\
\hline extracellular region part (GO:0044421) & 1555 & 57 & 33.09 & + & 1.72 & $3.49 \times 10^{-2}$ \\
\hline membrane (GO:0016020) & 4745 & 154 & 100.98 & + & 1.53 & $7.69 \times 10^{-7}$ \\
\hline organelle part (GO:0044422) & 3580 & 45 & 76.18 & - & 0.59 & $1.11 \times 10^{-2}$ \\
\hline intracellular organelle part (GO:0044446) & 3472 & 41 & 73.89 & - & 0.55 & $2.59 \times 10^{-3}$ \\
\hline nucleus (GO:0005634) & 3106 & 35 & 66.1 & - & 0.53 & $3.12 \times 10^{-3}$ \\
\hline organelle lumen (GO:0043233) & 1703 & 15 & 36.24 & - & 0.41 & $2.45 \times 10^{-2}$ \\
\hline intracellular organelle lumen (GO:0070013) & 1703 & 15 & 36.24 & - & 0.41 & $2.45 \times 10^{-2}$ \\
\hline membrane-enclosed lumen (GO:0031974) & 1703 & 15 & 36.24 & - & 0.41 & $2.45 \times 10^{-2}$ \\
\hline nuclear part (GO:0044428) & 1764 & 15 & 37.54 & - & 0.4 & $1.01 \times 10^{-2}$ \\
\hline Unclassified (UNCLASSIFIED) & 6062 & 78 & 129.0 & - & 0.6 & $0.00 \times 10$ \\
\hline \multicolumn{7}{|l|}{ GO molecular function complete } \\
\hline transporter activity & 861 & 39 & 18.32 & + & 2.13 & $1.71 \times 10^{-2}$ \\
\hline nucleic acid binding & 1988 & 15 & 42.31 & - & 0.35 & $6.66 \times 10^{-4}$ \\
\hline Unclassified & 6653 & 112 & 141.58 & - & 0.79 & $0.00 \times 10$ \\
\hline
\end{tabular}

Included categories had fold enrichment (number of DE genes divided by expected (Exp)) $>2.0$. For each Gene Ontology category, the number of genes in the reference list and those differentially expressed in the turkey are given. DE turkey genes were matched to the chicken gene reference list for analysis in PANTHER [38]. $p$-values are as determined by the binomial statistic. 
Table 4. Summary of PANTHER Overrepresentation Test of the 1241 unique differentially expressed (DE) genes in liver of domesticated turkeys after AFB 1 exposure as compared to controls.

\begin{tabular}{|c|c|c|c|c|c|c|}
\hline Category & $\begin{array}{l}\text { Gallus gallus-REFLIST } \\
\text { Genes (15789) }\end{array}$ & $\begin{array}{c}\text { Observed Turkey } \\
\text { Genes }\end{array}$ & Expected & over/under & Fold Enrichment & $p$-Value \\
\hline \multicolumn{7}{|l|}{ GO biological process complete } \\
\hline organelle fission (GO:0048285) & 135 & 17 & 4.52 & + & 3.76 & $2.53 \times 10^{-2}$ \\
\hline oxidation-reduction process (GO:0055114) & 549 & 46 & 18.39 & + & 2.50 & $1.11 \times 10^{-4}$ \\
\hline regulation of immune system process (GO:0002682) & 408 & 33 & 13.67 & + & 2.41 & $2.40 \times 10^{-2}$ \\
\hline signal transduction (GO:0007165) & 2057 & 114 & 68.92 & + & 1.65 & $2.19 \times 10^{-4}$ \\
\hline Signaling (GO:0023052) & 2205 & 122 & 73.88 & + & 1.65 & $6.80 \times 10^{-5}$ \\
\hline single organism signaling (GO:0044700) & 2201 & 121 & 73.74 & + & 1.64 & $1.15 \times 10^{-4}$ \\
\hline single-organism metabolic process (GO:0044710) & 1745 & 95 & 58.47 & + & 1.62 & $8.40 \times 10^{-3}$ \\
\hline cell communication (GO:0007154) & 2250 & 122 & 75.38 & + & 1.62 & $2.13 \times 10^{-4}$ \\
\hline cellular response to stimulus (GO:0051716) & 2657 & 135 & 89.02 & + & 1.52 & $1.45 \times 10^{-3}$ \\
\hline single-organism process (GO:0044699) & 6098 & 309 & 204.31 & + & 1.51 & $1.54 \times 10^{-16}$ \\
\hline response to stimulus (GO:0050896) & 3224 & 159 & 108.02 & + & 1.47 & $5.26 \times 10^{-4}$ \\
\hline single-organism cellular process (GO:0044763) & 4263 & 205 & 142.83 & + & 1.44 & $1.46 \times 10^{-5}$ \\
\hline regulation of cellular process (GO:0050794) & 4810 & 220 & 161.16 & + & 1.37 & $2.08 \times 10^{-4}$ \\
\hline regulation of biological process GO:0050789) & 5131 & 227 & 171.91 & + & 1.32 & $1.83 \times 10^{-3}$ \\
\hline biological regulation (GO:0065007) & 5521 & 244 & 184.98 & + & 1.32 & $4.20 \times 10^{-4}$ \\
\hline cellular process (GO:0009987) & 7267 & 307 & 243.48 & + & 1.26 & $1.04 \times 10^{-4}$ \\
\hline Unclassified & 6357 & 130 & 212.99 & - & 0.61 & $0.00 \times 10$ \\
\hline \multicolumn{7}{|l|}{ GO cellular component complete } \\
\hline mitochondrial inner membrane (GO:0005743) & 213 & 22 & 7.14 & + & 3.08 & $4.57 \times 10^{-3}$ \\
\hline mitochondrial membrane (GO:0031966) & 273 & 26 & 9.15 & + & 2.84 & $2.75 \times 10^{-3}$ \\
\hline mitochondrial envelope (GO:0005740) & 290 & 27 & 9.72 & + & 2.78 & $2.69 \times 10^{-3}$ \\
\hline organelle inner membrane (GO:0019866) & 239 & 22 & 8.01 & + & 2.75 & $2.60 \times 10^{-2}$ \\
\hline mitochondrial part (GO:0044429) & 395 & 30 & 13.23 & + & 2.27 & $3.65 \times 10^{-2}$ \\
\hline mitochondrion (GO:0005739) & 819 & 50 & 27.44 & + & 1.82 & $3.85 \times 10^{-2}$ \\
\hline membrane part (GO:0044425) & 3689 & 193 & 123.6 & + & 1.56 & $7.73 \times 10^{-9}$ \\
\hline cell periphery (GO:0071944) & 1888 & 98 & 63.26 & + & 1.55 & $7.45 \times 10^{-3}$ \\
\hline plasma membrane (GO:0005886) & 1834 & 95 & 61.45 & + & 1.55 & $1.15 \times 10^{-2}$ \\
\hline intrinsic component of membrane (GO:0031224) & 3244 & 166 & 108.69 & + & 1.53 & $2.94 \times 10^{-6}$ \\
\hline integral component of membrane (GO:0016021) & 3200 & 163 & 107.21 & + & 1.52 & $6.18 \times 10^{-6}$ \\
\hline Membrane(GO:0016020) & 4745 & 238 & 158.98 & + & 1.50 & $3.01 \times 10^{-10}$ \\
\hline Cell (GO:0005623) & 7948 & 328 & 266.29 & + & 1.23 & $4.09 \times 10^{-5}$ \\
\hline cell part (GO:0044464) & 7895 & 325 & 264.52 & + & 1.23 & $7.49 \times 10^{-5}$ \\
\hline Intracellular (GO:0005622) & 6948 & 279 & 232.79 & + & 1.20 & $3.08 \times 10^{-2}$ \\
\hline intracellular ribonucleoprotein complex GO:0030529) & 437 & 2 & 14.64 & - & $<0.20$ & $4.24 \times 10^{-2}$ \\
\hline ribonucleoprotein complex (GO:1990904) & 438 & 2 & 14.67 & - & $<0.20$ & $4.12 \times 10^{-2}$ \\
\hline Unclassified & 6062 & 115 & 203.10 & - & 0.57 & $0.00 \times 10$ \\
\hline \multicolumn{7}{|l|}{ GO molecular function complete } \\
\hline oxidoreductase activity (GO:0016491) & 486 & 38 & 16.28 & + & 2.33 & $3.68 \times 10^{-3}$ \\
\hline ion binding (GO:0043167) & 3114 & 144 & 104.33 & + & 1.38 & $3.63 \times 10^{-2}$ \\
\hline Unclassified & 6653 & 155 & 222.9 & - & 0.70 & $0.00 \times 10$ \\
\hline
\end{tabular}

DE turkey genes were matched to the chicken gene reference list for analysis in PANTHER [38]. For each, Gene Ontology category, the number of genes in the reference list and those differentially expressed in the turkey are given. Fold enrichment is the number of DE genes divided by Expected. $p$-values are as determined by the binomial statistic. 


\subsection{Differential Transcriptomic Expression: Eastern Wild vs. Domesticated Turkey}

\subsubsection{Control}

Comparison of the transcriptomes of control EW and DT birds found 774 DEGs (FDR $p$-value $<0.05$, $\log _{2} \mathrm{FC}=-8.826$ to 8.213 ), with 184 having $\log _{2} \mathrm{FC}>2.0$ (Figure 3, Table S5). Of the 184 genes, seven were shared in common in the EW vs. DT $\mathrm{AFB}_{1}$ comparisons (Figure 3). The shared loci included 5 genes up regulated in EW birds (ANGPTL3, CAMK4, LOC100538933 [probable ATP-dependent RNA helicase DDX60], LOC100545362 [ncRNA], LOC104912934 [ncRNA]), and two that were down regulated (LOC104910139 [ncRNA], LOC104915640 [KIAA1755 homolog]) when compared to DT. These shared genes are primarily metabolic and transcriptional regulators. In mammals, ANGPTL3 [angiopoietin-like 3] is a hepatokine involved in regulation of lipid and glucose metabolism and in the regulation of angiogenesis [37], CAMK4 [calcium/calmodulin-dependent protein kinase IV] is implicated in transcriptional regulation in immune and inflammatory responses [39], and DDX60 positively regulates DDX58/RIG-I- and IFIH1/MDA5-dependent type I interferon and interferon inducible gene expression [40].

\section{Wild vs Domesticated}

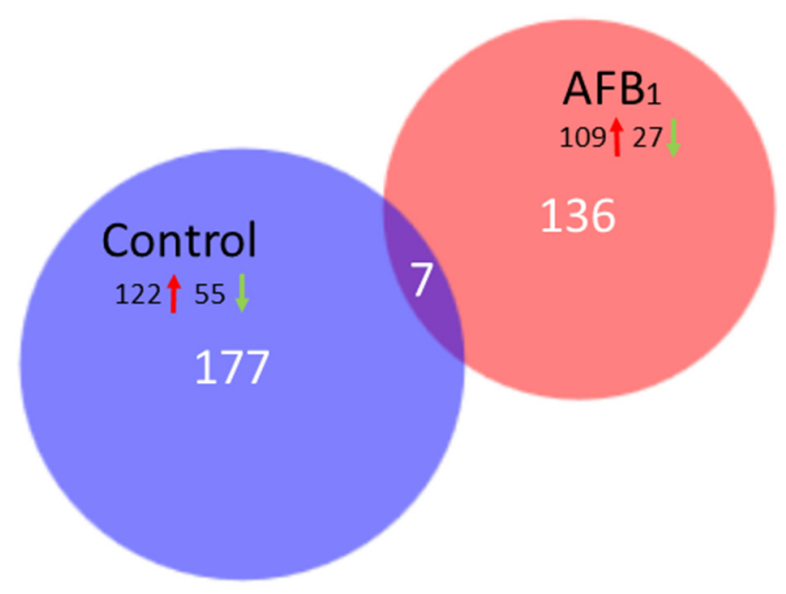

Figure 3. Distribution of differentially expressed of liver genes between turkey types (Wild and Domesticated). For each comparison, the number of genes with FDR $p$-value $<0.05$ and $\mid \log _{2} \mathrm{FCl}>2.0$ shared or unique to each treatment group are indicated. Circle size is proportional to the number of genes and direction of expression change $(\uparrow$ or $\downarrow$ ) is given for the genes in each group.

Of the 177 DEGs unique to the control group birds the majority (69\%) were up regulated in the wild birds as compared to the domesticated birds. GO analysis found only a single biological process category ("single-organism process" GO:0044699) enriched among these genes (fold enrichment $=1.66$, $p$-value $=4.15 \times 10^{-2}$ ). Interestingly, the up-regulated DEGs observed in the control-diet comparison also included glutathione S-transferase A3 (GSTA3). This gene was expressed at a 5.3-fold higher level $\left(\log _{2} \mathrm{FC}=2.313\right)$ in the EW birds when compared to the DT birds (Figure $\left.4 \mathrm{~A}\right)$, suggesting a higher constitutive expression in the former. 

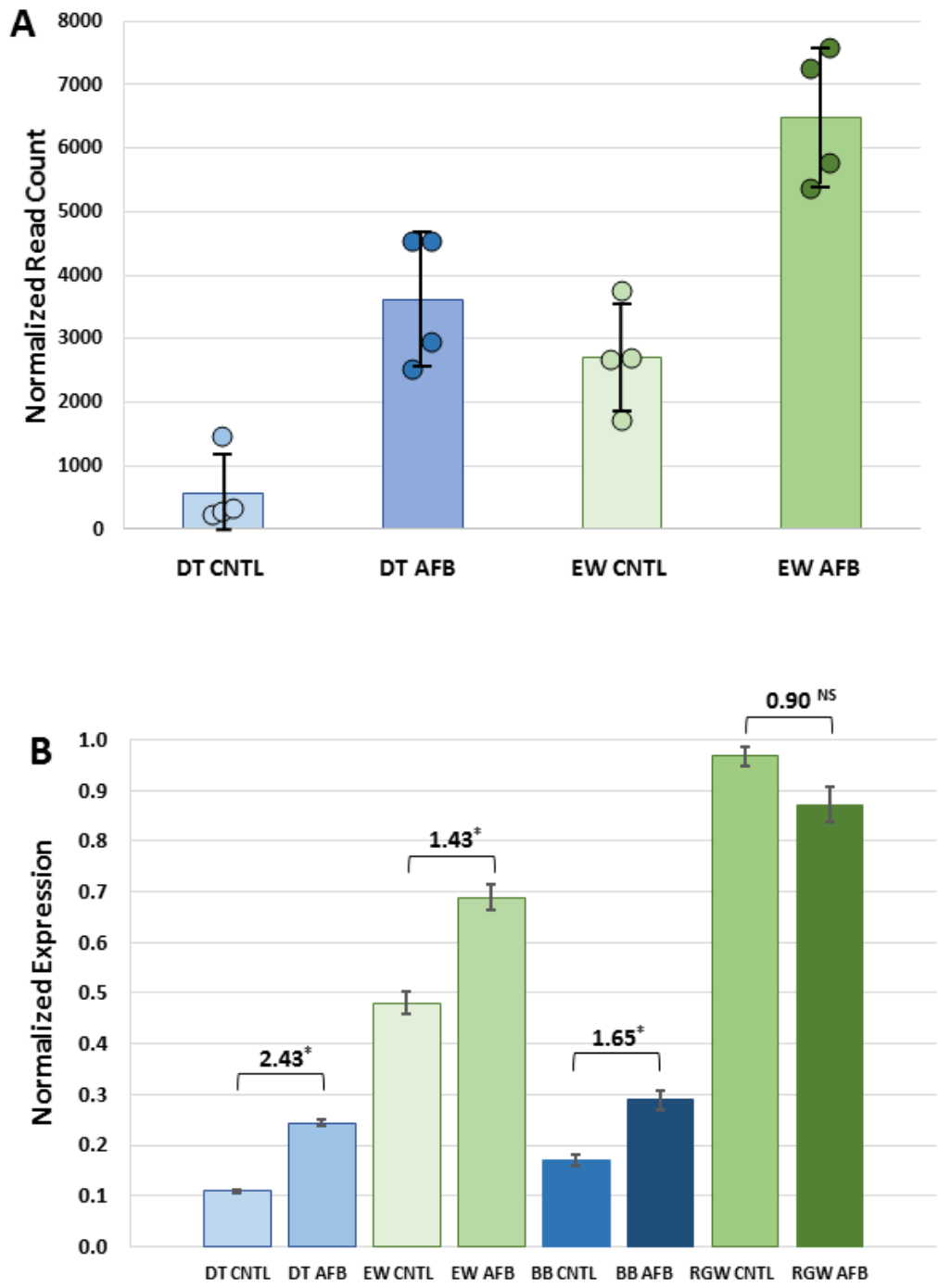

Figure 4. Effect of $\mathrm{AFB}_{1}$ on expression of GSTA3 in the livers of turkeys. (A) Mean normalized RNA-seq read counts. For each treatment group, individual read counts are indicated by closed circles. Error bars denote standard deviation of the mean. (B) Relative expression as measured by qRT-PCR. For each group the fold change $(\Delta \Delta \mathrm{Ct})$ between $\mathrm{AFB}_{1}$-treated and control birds is given. Asterisks denote significant comparisons ( $p$-value $<0.01)$.

The genes showing the greatest positive fold change was the Interferon-inducible iron-sulfur cluster-binding antiviral protein RSAD2, radical S-adenosyl methionine domain containing 2, with $\log _{2} \mathrm{FC}=8.2$ and the interferon alpha-inducible protein 27-like 2B (IFI27L2B, LOC100550948). In mammals, RSAD2 can inhibit a wide range of DNA and RNA viruses, and has also been shown to play a role in CD4+ T-cells activation and differentiation [41], whereas IFI27L2B mediates virus-induced apoptosis [42]. These suggest heightened immune system activity in the wild birds.

Two genes involved in cell cycle control and chromosomal replication were also expressed at a significantly higher level in the wild bird controls. $C D 1$, chromatin licensing and DNA replication factor 1 and MCM3, minichromosome maintenance complex component 3 had $\log _{2} \mathrm{FC}=2.74$ and 2.4, respectively (Table S5). Interestingly several other genes involved "cell cycle control" and "chromosomal replication" were also significantly up regulated in the wild birds, although with $\log _{2} \mathrm{FC}<2.0$ (Table S2). These included CDC45 (cell division cycle 45), DNA2 (DNA replication helicase/nuclease 2), the minichromosome maintenance complex components MCM2, MCM4, MCM5, MCM6, and MCM8, and POLE (DNA polymerase epsilon, catalytic subunit). These together with 
CD1 and MCM2 were components of the most significant Canonical Pathway identified by IPA $\left(p=1.1 \times 10^{-8}\right.$, ratio 0.25$)$. Genes showing the greatest negative fold change were GYG2 (glycogenin 2$)$, IQCD (IQ Motif Containing Protein D), and LOC100540418 (BPI fold-containing family C protein-like) (Table S5). GYG2 is involved in the initiation reactions of glycogen biosynthesis [43], and IQCD has been shown to interact with the RXR nuclear hormone receptor, and is thought to function as a transcriptional coactivator [44].

\subsection{2. $\mathrm{AFB}_{1}$ Treatment}

Comparison of the transcriptomes of EW and DT birds fed the $\mathrm{AFB}_{1}$ diet revealed 903 DEGs (FDR $p$-value $<0.05, \log _{2} \mathrm{FC}=-7.987$ to 9.262), of which, 143 had $\log _{2} \mathrm{FC}>2.0$ (Figure 3, Table S5). Of these 143 DEGs, 136 were unique to the $\mathrm{AFB}_{1}$-treated birds. The majority $(76 \%)$ of the DEGs were up regulated in EW relative to DT in a similar fashion to that seen for the control-group comparison. Unlike the control-fed groups, GO analysis found the DE genes from the $\mathrm{AFB}_{1}$ between-line comparison highly enriched in several biological process categories (Table 5) including processes related to coagulation, inflammatory response and apoptosis. For example, up regulated in EW relative to DT were three components of the blood clotting factor fibrinogen ( $F G A, F G B$, and $F G G)$ and several other coagulation-related genes (vitamin K-dependent coagulation factor IX (F9), serpin peptidase inhibitor, member 10 (SERPINA10), histidine-rich glycoprotein (HRG), serpin peptidase inhibitor, clade C (antithrombin), member 1 (SERPINC1)). Although down-regulated genes did not show significant enrichment for a particular bioprocess, EW birds may produce less of the pro-inflammatory cytokine IL-17A (LOC100546746).

Expression of many enzymes responsible for xenobiotic metabolism, with an emphasis on those with specificity towards $\mathrm{AFB}_{1}$, was significantly altered by the $\mathrm{AFB}_{1}$ treatment (Table 6). With a few exceptions, $\mathrm{AFB}_{1}$ largely caused down regulation of these genes in both types of turkeys when compared to controls; within the control groups, the number of DEGs was considerably smaller and the magnitude of expression changes was also smaller, but directionally similar. Hepatic expression of CYP and GST genes was typically greater in EW vs. DT. Five cytochrome P450 loci; CYP1A5 (cytochrome P450, family 1 , subfamily A, polypeptide 5, $\log _{2} \mathrm{FC}=2.404$ ), LOC100547030 (cytochrome P450 2W1-like, $\log _{2} \mathrm{FC}=5.87$ ), LOC100542486 (cytochrome P450 1A4, $\log _{2} \mathrm{FC}=3.150$ ), LOC100548433 (cytochrome P450 2K1-like, $\log _{2} \mathrm{FC}=3.025$ ), and LOC104915479 (cytochrome P450 2H1-like, $\log _{2} \mathrm{FC}=2.135$ ) were among the unique DEGs in the EW vs. DT comparison.

The turkey possesses six $\alpha$-GST cluster genes, all of which possess detectable enzymatic activities toward prototype substrates in a recombinant expression system [19], unlike hepatic forms. Expression of the GSTAs was significantly altered by $\mathrm{AFB}_{1}$ treatment. With the exception of GSTA3, GSTA1.1, 1.3, 2 and 4 were down regulated, while GSTA3 increased with dietary $\mathrm{AFB}_{1}$ in DT but not EW $\left(\log _{2} \mathrm{FC}=1.4667\right.$, Table 6). It is noteworthy that GSTA3 expression was significantly higher in EW birds when compared to DT birds for both control $\left(\log _{2} \mathrm{FC}=2.3130\right)$ and $\mathrm{AFB}_{1}\left(\log _{2} \mathrm{FC}=0.9211\right)$ group comparisons (Table 6, Figure 4A).

Expression differences in GSTA3 observed in RNA-seq read counts were confirmed by qRT-PCR. GSTA3 expression varied widely among treatment groups with experiment-wise threshold values $(\Delta \mathrm{Ct})$ ranging from 17.27 to 26.06. Expression of GSTA3 transcripts was significantly higher in $\mathrm{AFB}_{1}$-treated birds than controls for both genetic groups (EW, $p=0.0061$ and DT, $p=0.0036$ ). Relative GSTA3 expression was also similarly variable in the other commercial (BB) and wild-type birds (RGW) (Figure 4B) where GSTA3 expression was higher in $\mathrm{AFB}_{1}$-treated birds. This difference, however, was only significant in the BB comparison $(p=0.0015)$. Relative expression in BB birds was slightly higher than observed in the DT (Nicholas strain) birds and also higher in RGW birds (Rio Grande wild) when compared to EW. This result demonstrates that the differences observed in GSTA3 expression between the EW and DT birds is not unique to these genetic lines but is a broader, wild versus domesticated-bird phenomenon. 
Table 5. Summary of PANTHER Overrepresentation Test of the 136 unique differentially expressed (DE) genes in livers of Eastern wild turkeys after AFB 1 exposure as compared to domesticated turkey.

\begin{tabular}{|c|c|c|c|c|c|c|}
\hline GO Biological Process Complete & $\begin{array}{c}\text { Gallus gallus-REFLIST } \\
\text { Genes (15782) }\end{array}$ & $\begin{array}{c}\text { Observed Turkey } \\
\text { Genes }\end{array}$ & Expected & over/under & Fold Enrichment & $p$-Value \\
\hline L-serine biosynthetic process (GO:0006564) & ( & 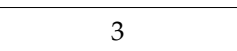 & 0.01 & + & $>100$ & $6.60 \times 10^{-4}$ \\
\hline blood coagulation, fibrin clot formation (GO:0072378) & 5 & 3 & 0.02 & + & $>100$ & $3.04 \times 10^{-3}$ \\
\hline plasminogen activation (GO:0031639) & 5 & 3 & 0.02 & + & $>100$ & $3.04 \times 10^{-3}$ \\
\hline L-serine metabolic process (GO:0006563) & 6 & 3 & 0.02 & + & $>100$ & $5.24 \times 10^{-3}$ \\
\hline zymogen activation (GO:0031638) & 9 & 4 & 0.03 & + & $>100$ & $1.15 \times 10^{-4}$ \\
\hline regulation of heterotypic cell-cell adhesion (GO:0034114) & 9 & 3 & 0.03 & + & $>100$ & $1.76 \times 10^{-2}$ \\
\hline fibrinolysis (GO:0042730) & 9 & 3 & 0.03 & + & $>100$ & $1.76 \times 10^{-2}$ \\
\hline negative regulation of endothelial cell apoptotic process (GO:2000352) & 11 & 3 & 0.03 & + & 87.84 & $3.20 \times 10^{-2}$ \\
\hline positive regulation of vasoconstriction (GO:0045907) & 12 & 3 & 0.04 & + & 80.52 & $4.14 \times 10^{-2}$ \\
\hline positive regulation of peptide hormone secretion (GO:0090277) & 30 & 4 & 0.09 & + & 42.94 & $1.36 \times 10^{-2}$ \\
\hline cell-matrix adhesion (GO:0007160) & 44 & 5 & 0.14 & + & 36.6 & $1.52 \times 10^{-3}$ \\
\hline coagulation (GO:0050817) & 65 & 5 & 0.20 & + & 24.78 & $1.02 \times 10^{-2}$ \\
\hline blood coagulation (GO:0007596) & 65 & 5 & 0.20 & + & 24.78 & $1.02 \times 10^{-2}$ \\
\hline cell-substrate adhesion (GO:0031589) & 66 & 5 & 0.20 & + & 24.4 & $1.10 \times 10^{-2}$ \\
\hline hemostasis (GO:0007599) & 66 & 5 & 0.20 & + & 24.4 & $1.10 \times 10^{-2}$ \\
\hline positive regulation of protein secretion (GO:0050714) & 69 & 5 & 0.21 & + & 23.34 & $1.36 \times 10^{-2}$ \\
\hline positive regulation of peptide secretion (GO:0002793) & 78 & 5 & 0.24 & + & 20.65 & $2.46 \times 10^{-2}$ \\
\hline alpha-amino acid metabolic process (GO:1901605) & 104 & 6 & 0.32 & + & 18.58 & $4.71 \times 10^{-3}$ \\
\hline small molecule metabolic process (GO:0044281) & 816 & 13 & 2.53 & + & 5.13 & $4.46 \times 10^{-3}$ \\
\hline single-organism metabolic process (GO:0044710) & 1775 & 19 & 5.51 & + & 3.45 & $3.17 \times 10^{-3}$ \\
\hline single-organism process (GO:0044699) & 6214 & 39 & 19.29 & + & 2.02 & $5.62 \times 10^{-5}$ \\
\hline Unclassified (UNCLASSIFIED) & 6196 & 6 & 19.24 & - & 0.31 & $0.00 \times 10$ \\
\hline
\end{tabular}

DE turkey genes were matched to the chicken gene reference list for analysis in PANTHER [38]. For each, Gene Ontology category, the number of genes in the reference list and those differentially expressed in the turkey are given. Fold enrichment is the number of DE genes divided by Expected. $p$-values are as determined by the binomial statistic. 
Table 6. Differential expression (DE) of genes from major enzyme groups responsible for metabolizing xenobiotic chemicals.

\begin{tabular}{|c|c|c|c|c|c|c|c|c|c|}
\hline \multirow{2}{*}{ ID } & \multicolumn{2}{|c|}{ EW AFB vs. CNTL } & \multicolumn{2}{|c|}{ DT AFB vs. CNTL } & \multicolumn{2}{|c|}{ CNTL EW vs. DT } & \multicolumn{2}{|c|}{ AFB EW vs. DT } & \multirow{2}{*}{ Description } \\
\hline & FDR Pval & $\log _{2} \mathrm{FC}$ & FDR Pval & $\log _{2} \mathrm{FC}$ & FDR Pval & $\log _{2} \mathrm{FC}$ & FDR Pval & $\log _{2} \mathrm{FC}$ & \\
\hline AKR1D1 & 0.9964 & 0.0559 & 0.0000 & -2.6518 & 0.0000 & -3.2445 & 0.2276 & -0.5988 & aldo-keto reductase family 1, member D1 \\
\hline ALDH2 & 0.0190 & -0.8404 & 0.0000 & -1.5779 & 0.1522 & -0.5354 & 0.9648 & 0.1539 & aldehyde dehydrogenase 2 family (mitochondrial) \\
\hline AOX1 & 0.0000 & 2.1137 & 0.0010 & 0.8410 & 0.0574 & -0.6975 & 0.2037 & 0.5258 & aldehyde oxidase 1 \\
\hline COMT & 0.0000 & -2.5729 & 0.0000 & -2.8723 & 0.0373 & -0.7682 & 0.2064 & -0.5319 & catechol-O-methyltransferase \\
\hline CYP1A5 & 0.0000 & -6.0043 & 0.0000 & -9.2792 & 0.0721 & -0.8105 & 0.0000 & 2.4042 & cytochrome P450, family 1 , subfamily A, polypeptide 5 \\
\hline СУРЗАЗ37 & 0.0640 & -0.9576 & 0.0000 & -2.8884 & 0.0007 & -1.5099 & 0.8268 & 0.3698 & cytochrome P450 3A37 \\
\hline СУР $3 А 80$ & 0.9731 & -0.1270 & 0.0052 & -1.0866 & 0.0022 & -1.7031 & 0.3001 & -0.8022 & cytochrome P450 3A80 \\
\hline EPHX1 & 0.0000 & 3.0994 & 0.0007 & 0.9636 & 0.2271 & -0.8719 & 0.0009 & 1.2112 & epoxide hydrolase 1 , microsomal (xenobiotic) \\
\hline EPHX2 & 0.0000 & -2.7512 & 0.0000 & -2.5788 & 0.4757 & 0.4301 & 0.8342 & 0.2075 & epoxide hydrolase 2 , cytoplasmic \\
\hline EPHX4 & 0.0000 & 3.1365 & 0.0091 & 2.4479 & 1.0000 & 0.3859 & 0.1409 & 1.0154 & epoxide hydrolase 4 \\
\hline GSTA1.1* & 0.0000 & -2.0007 & 0.0000 & -2.6584 & 0.0066 & 1.3021 & 0.0000 & 1.9010 & glutathione $S$-transferase alpha class A1.1 \\
\hline GSTA1.3 * & 0.0004 & -1.0804 & 0.0000 & -1.6746 & 0.1740 & 0.6098 & 0.0003 & 1.1419 & glutathione $S$-transferase alpha class A1.3 \\
\hline GSTA2 & 0.0000 & -1.7332 & 0.0000 & -1.9211 & 0.1019 & 0.5386 & 0.0098 & 0.6713 & glutathione $S$-transferase 2 \\
\hline GSTA3 & 0.8469 & 0.1297 & 0.0014 & 1.4667 & 0.0000 & 2.3130 & 0.0063 & 0.9211 & glutathione $S$-transferase 3 \\
\hline GSTA4 & 0.0000 & -5.9578 & 0.0000 & -6.4058 & 0.3086 & 0.5690 & 0.0204 & 0.9569 & glutathione $S$-transferase 4 \\
\hline GSTK1 & 0.0000 & -1.8072 & 0.0000 & -2.9850 & 0.1814 & -0.5583 & 0.0773 & 0.5713 & glutathione $S$-transferase kappa 1 \\
\hline GSTZ1 & 0.0000 & -3.3639 & 0.0000 & -4.1131 & 1.0000 & 0.0517 & 0.0325 & 0.7477 & glutathione $S$-transferase zeta 1 \\
\hline LOC100538434 & 0.0000 & 1.7178 & 0.7570 & 0.1451 & 0.0038 & -0.9746 & 0.3530 & 0.5480 & cytochrome P450 4B1-like \\
\hline LOC100538440 & 0.0000 & -2.8970 & 0.0000 & -2.2682 & 0.1163 & 0.5550 & 0.9682 & -0.1256 & glutathione $S$-transferase theta-1-like \\
\hline LOC100538588 & 0.0025 & -1.1881 & 0.0000 & -3.4884 & 0.0001 & -1.2845 & 0.0758 & 0.9622 & cytochrome P450 4B1-like \\
\hline LOC100538595 & 0.0000 & -7.0046 & 0.0000 & -8.5660 & 1.0000 & 0.0523 & 0.1895 & 1.5495 & glutathione $S$-transferase theta- 1 \\
\hline LOC100542486 & 0.0000 & -3.3050 & 0.0000 & -7.4005 & 0.1187 & -0.8954 & 0.0000 & 3.1496 & cytochrome P450 1A4 \\
\hline LOC100543147 & 0.0000 & -1.9129 & 0.0001 & -1.0244 & 0.0097 & 0.8235 & 0.9927 & -0.1181 & cytochrome P450 2U1 \\
\hline LOC100543474 & 0.0000 & 4.4089 & 0.0000 & 3.2044 & 0.6256 & -0.4228 & 0.0227 & 0.7294 & glutathione $S$-transferase omega-1-like \\
\hline LOC100544448 & 0.0000 & -3.1080 & 0.0000 & -3.1865 & 1.0000 & -0.1757 & 1.0000 & -0.1579 & cytochrome P450 2C9-like \\
\hline LOC100544938 & 0.0000 & -1.6254 & 0.0052 & -0.8255 & 0.8684 & 0.3729 & 0.3538 & -0.4894 & cytochrome P450 26B1 \\
\hline LOC100545163 & 0.0000 & -2.7394 & 0.0000 & -3.5785 & 0.0404 & -0.7668 & 1.0000 & 0.0207 & alcohol dehydrogenase 1 \\
\hline LOC100545251 & 0.0055 & -0.8765 & 0.0000 & -1.7618 & 0.6466 & 0.3201 & 0.0085 & 1.1514 & sulfotransferase 1C1-like \\
\hline LOC100545313 & 0.0011 & -6.6206 & 0.0000 & -12.9085 & 0.0662 & 2.5030 & 0.0071 & 9.2625 & sulfotransferase 6B1-like \\
\hline LOC100545337 & 0.0042 & -0.8258 & 0.4111 & 0.3711 & 0.0116 & 1.3434 & 1.0000 & 0.0879 & sulfotransferase family cytosolic 2B member 1-like \\
\hline LOC100545469 & 0.0000 & -7.4792 & 0.0000 & -12.4538 & 0.8899 & -0.3159 & 0.0330 & 4.6071 & sulfotransferase 6B1-like \\
\hline LOC100545683 & 0.0000 & -2.4276 & 0.0000 & -5.5488 & 0.3422 & -0.8455 & 0.0915 & 2.2195 & cytochrome P450 2H1-like \\
\hline LOC100546724 & 0.0000 & 1.8339 & 0.0095 & 0.8064 & 0.1178 & -0.9930 & 1.0000 & -0.0121 & cytochrome P450 2K4-like \\
\hline LOC100546874 & 0.0169 & 0.7907 & 0.0000 & 0.9012 & 1.0000 & 0.0100 & 0.9251 & -0.1538 & cytochrome P450 2W1-like \\
\hline LOC100547030 & 0.0000 & -7.6458 & 0.0000 & -13.6234 & 1.0000 & -0.2262 & 0.0010 & 5.8718 & cytochrome P450 2W1-like \\
\hline LOC100547576 & 0.0000 & -4.3115 & 0.0000 & -5.2719 & 0.0014 & -1.0131 & 1.0000 & -0.1127 & UDP-glucuronosyltransferase 1-1-like \\
\hline LOC100547627 & 0.7689 & 0.1433 & 0.0094 & -0.7229 & 0.0023 & -1.0592 & 0.7311 & -0.2480 & sulfotransferase family cytosolic $1 \mathrm{~B}$ member 1 \\
\hline LOC100547794 & 0.0284 & 0.7020 & 0.9613 & 0.0689 & 0.9308 & -0.3488 & 0.7143 & 0.2327 & cytochrome P450 2J2-like \\
\hline LOC100547885 & 0.0011 & -0.9841 & 0.0000 & -2.4195 & 0.0453 & -0.6672 & 0.0321 & 0.7153 & UDP-glucuronosyltransferase 1-1-like \\
\hline LOC100548173 & 0.0000 & 3.7249 & 0.0000 & 2.5969 & 1.0000 & -0.3391 & 0.1461 & 0.7080 & galactosylgalactosylxylosylprotein 3-betaglucuronosyltransferase 1-like \\
\hline
\end{tabular}


Table 6. Cont.

\begin{tabular}{|c|c|c|c|c|c|c|c|c|c|}
\hline \multirow{2}{*}{ ID } & \multicolumn{2}{|c|}{ EW AFB vs. CNTL } & \multicolumn{2}{|c|}{ DT AFB vs. CNTL } & \multicolumn{2}{|c|}{ CNTL EW vs. DT } & \multicolumn{2}{|c|}{ AFB EW vs. DT } & \multirow{2}{*}{ Description } \\
\hline & FDR Pval & $\log _{2} \mathrm{FC}$ & FDR Pval & $\log _{2} \mathrm{FC}$ & FDR Pval & $\log _{2} \mathrm{FC}$ & FDR Pval & $\log _{2} \mathrm{FC}$ & \\
\hline LOC100548279 & 0.0000 & -7.9193 & 0.0000 & -11.0735 & 0.5445 & -0.5533 & 0.0906 & 2.5242 & cytochrome P450 2K4-like \\
\hline LOC100548322 & 0.0000 & -5.6388 & 0.0000 & -7.6409 & 0.0002 & -1.2226 & 0.0429 & 0.7206 & cytochrome P450 2D17 \\
\hline LOC100548433 & 0.0000 & -5.3627 & 0.0000 & -8.5915 & 1.0000 & -0.1464 & 0.0000 & 3.0249 & cytochrome P450 2K1-like \\
\hline LOC100548965 & 0.0027 & 1.2412 & 0.4561 & 0.2791 & 0.5805 & 0.4725 & 0.0144 & 1.3798 & cytochrome P450 2J3-like \\
\hline LOC100549160 & 0.0000 & -1.5607 & 0.0000 & -1.7517 & 0.0335 & -0.7103 & 0.3717 & -0.5706 & cytochrome P450 4F22 \\
\hline LOC100549268 & 0.0000 & 2.8734 & 0.0067 & 1.6835 & 1.0000 & -0.3799 & 0.2658 & 0.7421 & aldehyde oxidase 2-like \\
\hline LOC100549312 & 0.3177 & 0.3574 & 0.0000 & -1.5738 & 0.0000 & -1.9158 & 1.0000 & -0.0363 & UDP-glucuronosyltransferase 2C1-like \\
\hline LOC100549991 & 0.0000 & -1.7655 & 0.0000 & -1.6943 & 0.0002 & 1.3894 & 0.0039 & 1.2611 & arylamine $N$-acetyltransferase, liver isozyme \\
\hline LOC100550430 & 0.0512 & -0.6659 & 0.0000 & -1.3736 & 0.2945 & -0.4855 & 0.9495 & 0.1737 & cytochrome P450 4F22 \\
\hline LOC104909216 & 0.0925 & 3.6677 & 0.0207 & 4.6262 & 1.0000 & 0.0000 & 0.5908 & -1.0481 & cytochrome P450 2J6-like \\
\hline LOC104909734 & 0.0000 & -6.4443 & 0.0023 & -2.1011 & 0.0000 & 4.1441 & 1.0000 & -0.2356 & sulfotransferase family cytosolic $2 \mathrm{~B}$ member 1-like \\
\hline LOC104910746 & 0.0000 & -3.6385 & 0.0000 & -5.1988 & 0.7764 & -0.3620 & 0.1896 & 1.1405 & alcohol dehydrogenase 1-like \\
\hline LOC104911955 & 0.3696 & -0.4051 & 0.0000 & -1.7954 & 0.0045 & -1.2985 & 1.0000 & 0.0458 & cytochrome $\mathrm{P} 4502 \mathrm{H} 2$ \\
\hline LOC104912373 & 0.0000 & 6.1224 & 0.0000 & 7.7909 & 0.2163 & 2.2765 & 0.2724 & 0.5912 & sulfotransferase 6B1-like \\
\hline LOC104912427 & 0.0001 & 0.8626 & 0.0006 & 0.8049 & 0.7651 & -0.3468 & 0.3464 & -0.3463 & cytochrome P450 2J2-like \\
\hline LOC104912428 & 0.1738 & 0.5765 & 1.0000 & 0.0281 & 0.2879 & 0.5209 & 0.0401 & 1.0161 & cytochrome P450 2J2-like \\
\hline LOC104912494 & 0.0006 & 1.5962 & 0.0373 & 0.5871 & 1.0000 & -0.1563 & 0.3537 & 0.7988 & cytochrome P450 2J2-like \\
\hline LOC104915391 & 0.0000 & -4.4041 & 0.0000 & -4.5429 & 1.0000 & 0.2453 & 0.9573 & 0.3281 & sulfotransferase family cytosolic $2 \mathrm{~B}$ member 1-like \\
\hline LOC104915445 & 0.0000 & -3.6108 & 0.0000 & -4.2325 & 0.0262 & -0.8559 & 0.9682 & -0.2891 & alcohol dehydrogenase 1-like \\
\hline LOC104915446 & 0.0000 & -3.8678 & 0.0000 & -5.4661 & 0.1525 & -0.6518 & 0.4129 & 0.8857 & alcohol dehydrogenase 1-like \\
\hline LOC104915473 & 0.0000 & 1.5141 & 0.8643 & 0.0874 & 0.8777 & -0.3084 & 0.0010 & 1.0674 & UDP-glucuronosyltransferase 1-9-like \\
\hline LOC104915474 & 0.8756 & -0.1560 & 0.0000 & -3.7112 & 0.0000 & -2.5312 & 0.0418 & 0.9617 & UDP-glucuronosyltransferase 1-6-like \\
\hline LOC104915476 & 0.0006 & 1.6704 & 0.9112 & 0.1504 & 0.4764 & -1.0151 & 0.6292 & 0.4445 & UDP-glucuronosyltransferase 1-1-like \\
\hline LOC104915477 & 0.0000 & -4.3026 & 0.0000 & -6.1630 & 1.0000 & 0.0675 & 0.0160 & 1.8961 & UDP-glucuronosyltransferase 1-6 pseudogene \\
\hline LOC104915478 & 0.0000 & -1.7304 & 0.0000 & -3.7892 & 1.0000 & 0.1939 & 0.0017 & 2.2036 & UDP-glucuronosyltransferase 1-1-like \\
\hline LOC104915479 & 0.0000 & -2.4027 & 0.0000 & -5.5537 & 0.1838 & -0.9621 & 0.0384 & 2.1351 & cytochrome P450 2H1-like \\
\hline LOC104915586 & 0.0000 & -5.9323 & 0.0090 & -2.7687 & 0.0023 & 3.1518 & 1.0000 & -0.0267 & sulfotransferase family cytosolic $2 \mathrm{~B}$ member 1-like \\
\hline LOC104915609 & 0.0022 & -3.8661 & 0.0686 & -3.9012 & 0.8037 & 1.2048 & 1.0000 & 1.5781 & cytochrome P450 2C19-like \\
\hline LOC104915610 & 0.0000 & 3.8631 & 0.0000 & 3.5278 & 0.9437 & -0.6231 & 0.9255 & -0.3368 & cytochrome P450 2C4-like \\
\hline LOC104916399 & 0.0000 & -6.0701 & 0.0000 & -7.5516 & 0.5648 & 0.6141 & 0.4295 & 2.0569 & cytochrome P450 2C27-like \\
\hline LOC104916553 & 0.0000 & -4.9703 & 0.0000 & -3.9795 & 0.5369 & 0.6853 & 0.9367 & -0.3716 & sulfotransferase family cytosolic $2 \mathrm{~B}$ member 1-like \\
\hline LOC104916909 & 0.0000 & -5.6085 & 0.0000 & -7.0458 & 0.5315 & 0.5373 & 0.1227 & 1.9411 & cytochrome P450 2C31-like \\
\hline NQO1 & 0.7812 & -0.1408 & 0.0008 & -0.8283 & 1.0000 & -0.1435 & 0.2145 & 0.4945 & NAD(P)H dehydrogenase, quinone 1 \\
\hline NQO2 & 0.0000 & -0.9071 & 0.4267 & -0.2242 & 0.4389 & 0.3990 & 0.5130 & -0.3430 & $\mathrm{NAD}(\mathrm{P}) \mathrm{H}$ dehydrogenase, quinone 2 \\
\hline PTGS1 & 0.0000 & 1.4444 & 0.1729 & 0.5413 & 0.9517 & -0.4782 & 0.5266 & 0.3552 & prostaglandin-endoperoxide synthase 1 \\
\hline PTGS2 & 0.7963 & 0.1315 & 0.0000 & 1.3365 & 0.1157 & 0.7544 & 0.1495 & -0.5069 & prostaglandin-endoperoxide synthase 2 \\
\hline SULT4A1 & 0.1141 & -0.6315 & 0.0039 & -0.8113 & 1.0000 & 0.3027 & 0.4515 & 0.4192 & sulfotransferase family $4 \mathrm{~A}$, member 1 \\
\hline SULT6B1 & 0.0457 & -1.6954 & 0.0001 & -2.6041 & 1.0000 & 0.0540 & 0.7545 & 0.9577 & sulfotransferase family, cytosolic, 6B, member 1 \\
\hline TPMT & 0.9701 & 0.0725 & 0.0017 & -0.7106 & 0.8466 & -0.2968 & 0.2312 & 0.4402 & thiopurine S-methyltransferase \\
\hline UGT8 & 0.0000 & 1.7926 & 0.0000 & 1.1497 & 0.5752 & -0.3194 & 0.6356 & 0.2705 & UDP glycosyltransferase 8 \\
\hline
\end{tabular}

Genes included were significant (FDR $p$-value $<0.05$ ) in at least one comparison. Comparisons highlighted in green are down regulated and those in red up regulated. Cytochrome P450 $(\mathrm{CYP})$ and glutathione S-transferase (GST) family members shown to have in vitro activity towards $\mathrm{AFB}_{1}$ and its metabolites in turkey are indicated in bold. ${ }^{*}$ Due to similarity, these likely include transcripts assignable to GSTA1.1, A1.2, and A1.3. 


\section{Discussion}

When compared to their domestic relatives, wild turkeys are relatively resistant to aflatoxicosis. This difference is largely due to functional hepatic GSTA-mediated detoxification activity of the bioactive electrophilic AFBO intermediate that is completely lacking in domesticated birds [20]. The present data indicates other pathways may also account for difference in $\mathrm{AFB}_{1}$ susceptibility, such as cellular regulation, modulation of apoptosis, inflammatory responses, and other pathways relevant to $\mathrm{AFB}_{1}$ pathogenesis. The liver is the principal organ of $\mathrm{AFB}_{1}$ bioactivation and detoxification $[6,21,22,24,45]$. In turkeys, $\mathrm{AFB}_{1}$ causes reduced feed intake, weight gain, and immunological function in a dose-dependent fashion [46,47]. Dietary exposure in poultry causes lipid accumulation, resulting in hepatomegaly and increases in liver:body weight ratios [48-50]. During the 14 day exposure, decreased relative liver mass initially occurred in both EW and DT consistent with that observed in chickens [49] and wild turkeys [9].

Numerous significant DEGs occurring in the livers of $\mathrm{AFB}_{1}$-treated birds have potential roles in lipid metabolism or accumulation. $\mathrm{AFB}_{1}$ is known to alter lipid metabolism and increase lipid content resulting in pale or yellowed pigmentation [46]. Dietary $\mathrm{AFB}_{1}$ primarily down regulated several hepatic apolipoprotein genes (cofactors in lipid binding and transport) in the turkey, and dis-regulation of genes, such as ANGTPL3, would have direct effects on lipids. Significant up regulation of ANGTPL3 was observed for both EW and DT birds treated with $\mathrm{AFB}_{1}$. This would likely stimulate synthesis of plasma triglycerides (TG) via the inhibition of lipoprotein lipase (LPL) activity. In both $\mathrm{AFB}_{1}$-treated groups, $L P L$ was significantly down regulated $\left(\log _{2} \mathrm{FC}=-2.905\right.$ and -6.032 in EW and DT birds, respectively). LPL functions in the hydrolysis of triglycerides in lipoproteins and is essential to lipid metabolism and storage. Significant down regulation of LPL was also observed in our previous analyses of $\mathrm{AFB}_{1}$-treated domesticated Orlopp turkeys [26] and decreased expression of LPL occurs in $\mathrm{AFB}_{1}$-treated chickens [50].

As expected, the significant hepatic DEGs included the Phase I and II detoxifying enzymes that we have shown are relevant to $\mathrm{AFB}_{1}$ exposure in turkeys (Table 6). Previous studies have demonstrated efficient epoxidation by hepatic turkey cytochromes CYP1A5 and CYP3A37 [16]. At environmentally-relevant hepatic concentrations ( $<50 \mathrm{uM})$ CYP1A5 bioactivates the majority $(\sim 98 \%)$ of $\mathrm{AFB}_{1}[17,21]$, whereas CYP3A37 predominates at much higher substrate concentrations unlikely to be achieved in the livers of exposed animals [16]. Based on RNA-seq, it is clear that dietary AFB significantly down regulated CYP1A5 in both EW and DT birds, but more significantly so in DT. This result is at odds with our earlier findings in another strain of DT (Orlopp) where almost no expression change was observed for CYP1A5 and CYP3A37, and where none of the transcripts associated with CYP genes had significant $D E$ as a result of $\mathrm{AFB}_{1}$ treatment [26]. Significant down regulation of CYP1A5 in response to $\mathrm{AFB}_{1}$ was also observed in ducks, another avian species with high $\mathrm{AFB}_{1}$ susceptibility [51]. Several other P450 genes in addition to $1 A 5$ and $3 A 37$ had significant DE in the present study (Table 6), including both CYP2W1 and CYP2K1. Interestingly, these genes have been shown in other species to activate $\mathrm{AFB}_{1}$ into cytotoxic products [52,53]. We have found CYP2W1-like transcripts to have significant DE in DT embryos challenged with $\mathrm{AFB}_{1}$ [28]. Down regulation of CYP1A5 in both EW and DT birds could affect their overall ability to bioactivate $\mathrm{AFB}_{1}$. However, as this expression change was seen in both bird types, it does not account for the differences seen in $A_{F B}$ susceptibility [16].

Expression of GSTs with affinity toward AFBO is a known predictor of relative $\mathrm{AFB}_{1}$ resistance [20]. Constitutive expression of GSTA3, the ortholog to the putative AFB 1 -protective GSTA3 isoform in mice [18] was significantly higher in EW than in DT birds. Dietary $\mathrm{AFB}_{1}$ caused significant down-regulation of hepatic $\alpha$-class GSTs, with the exception of GSTA3, where increased expression of this isoform was observed in the $\mathrm{AFB}_{1}$-treated DT group. This pattern was also observed in the qRT experiments of other wild (RGW) and domesticated (BB) turkeys. A similar pattern of GSTA3 expression in response to $\mathrm{AFB}_{1}$ was also observed in turkey embryos early after exposure, where small increases were observed in DT [28] and in ducks [51]. 
Expression of GSTA3 mRNA in turkeys is not correlated with $\mathrm{AFB}_{1}$ sensitivity in that domesticated birds lack hepatic GST-mediated AFBO conjugating activity [19], despite expression of GSTA3. Hepatic cytosols isolated from wild turkeys possess functional AFBO-trapping GSTs [20]. While hepatic GSTs in DT lack detoxification activity, with or without $\mathrm{AFB}_{1}$ treatment, increased GSTA3 expression in DT in response to $\mathrm{AFB}_{1}$ may reflect a greater inflammatory response or perhaps an indicator of hepatocyte injury. Although GSTs are toxicologically important for their role in "trapping" electrophilic intermediates by conjugating with the nucleophilic GSH, they may also play a role in cell signaling through binding of non-substrate ligands to mediate cell proliferation and cell death [54]. Up regulation of GSTAs may also reflect antioxidant functions as $\mathrm{AFB}_{1}$, exposure in poultry can lead to oxidative stress and lipid peroxidation $[55,56]$. When combined, these results support the hypothesis that the greater ability of wild turkeys to detoxify $\mathrm{AFB}_{1}$ is related to higher constitutive expression of GSTA3, coupled with an inherited (genetic) difference in functional expression in domesticated birds. Expression in these CYP and GSTAs suggests that the physiological response to $\mathrm{AFB}_{1}$ is mediated through genes not experimentally linked in the turkey to $\mathrm{AFB}_{1}$ metabolism.

Up regulation of transcription factors and metabolic inhibitors characterized the shared response to $\mathrm{AFB}_{1}$. Taken together, these are genes that comprise the molecular mechanisms underlying aflatoxicosis. Recurrent themes amongst the many DEGs of $\mathrm{AFB}_{1}$-treated birds are linked by functional analysis to inflammation, apoptosis, the cell cycle (cancer), or lipid regulation, suggesting common underlying regulation. For example, recent studies of $\mathrm{AFB}_{1}$-induced hepatocellular carcinoma have examined regulatory ncRNAs (miRNA and lncRNA) [57,58]. Studies in the rat, another $\mathrm{AFB}_{1}$-susceptible species, have found coincident DE of transcripts that are related to these same functions and specific lncRNAs in hepatocellular carcinomas $[59,60]$. Our study of miRNA expression in the same turkey liver tissues used in the present study is currently underway (Coulombe, unpublished).

Transcriptome analysis not only includes genes responding to the presence of $\mathrm{AFB}_{1}$, but also reveals genes dis-regulated as a response to toxic insult. Significant up regulation was seen for several vasoactive peptides, including, neuropeptide $Y(N P Y)$, somatostatin (SST), substance P (tachykinin, $T A C 1$ ), and vasoactive intestinal peptide (VIP), suggesting altered sinusoidal blood flow with $\mathrm{AFB}_{1}$ treatment. Also, affected were extracellular matrix proteins including glycoproteins (e.g., HAPLN1 and HAPLN3), protein receptors (KERA, LAMB3, LUM, LRRN2, and LRRN3), proteinase inhibitors (TIMP4), signaling molecules (SFRP1, Wnt6 and 7a), and structural proteins (COL10A1, FRAS1). Expression of the majority of the ADAM metallopeptidases was altered in $\mathrm{AFB}_{1}$ treatment (Table $\mathrm{S} 2$ ). Some of these proteases are thought to be involved in regulating matrix degradation [61]. Unique response in the EW birds was seen in genes that negatively regulate cellular processes, components of the extracellular matrix and accumulation of coagulation factors. DT birds showed greater up regulation of genes responding to inflammation, which was likely due to the reduced ability to detoxify AFBO. Dis-regulation of extracellular matrix proteins is a resulting effect of chronic liver injury [32]. Aflatoxin inhibits cell-mediated immunity in domestic poults $[47,62]$ with the suppression of lymophoblastogenesis [9], T-helper, or cytotoxic T-cell activity [63].

Multiple genes involved in pathways of coagulation (FGA, FGB, FGG, F9, HRG, SERPINA10, and SERPINC1) were expressed at higher levels in EW as compared to DT, where they were among the genes with the highest negative fold change. Lower expression of coagulation factors was also seen in livers of domesticated turkey embryos after just 5 days of exposure to $\mathrm{AFB}_{1}$ [28]. $\mathrm{AFB}_{1}$ has been shown to increase blood clotting times in poultry $[64,65]$ and activities of coagulation factors, such as $\mathrm{F} 9$, were reduced by dietary $\mathrm{AFB}_{1}$ in chickens $[50,65]$. Effects on hemostasis are more dramatic in turkeys than chickens [66]. In comparison, only small non-significant increases in prothrombin times were seen in wild turkeys exposed to $\mathrm{AFB}_{1}$ [9], which is consistent with the gene expression patterns observed in the liver transcriptomes.

In a previous comparison of EW and DT after in ovo exposure [28], we used RNA-seq to examine gene expression responses to $\mathrm{AFB}_{1}$ in the embryonic hepatic transcriptomes and identified gene expression effects dependent on exposure time and turkey type. Most notable in turkey embryos 
was the more rapid response of the DT, which was likely due to their lack of GST activity towards the AFBO-epoxide. The present study was designed to contrast gene expression responses in the hepatic transcriptome of growing domesticated and wild turkeys during $\mathrm{AFB}_{1}$ exposure. In conclusion, our findings emphasize the differential response of these genetically distinct birds, demonstrating significant differences in expression of Phase I and Phase II genes and in genes important in cellular regulation, modulation of apoptosis, and inflammatory responses. The molecular basis for the differences in $\mathrm{AFB}_{1}$ detoxification observed between EW and DT birds, and the mechanism of GSTA silencing in DT remain under investigation.

\section{Materials and Methods}

This study used two turkey subspecies previously demonstrated to vary in $\mathrm{AFB}_{1}$-detoxifying GST activity. Eggs from domesticated (DT = Nicholas) and a wild subspecies (Eastern wild $=\mathrm{EW}$, Meleagris gallopavo silvestris) were obtained from Privett Hatchery (Portales, NM, USA) and hatched at Utah State University. Birds were sexed by PCR [67]. Male turkey poults were maintained on an ad libitum standard grow-up soy-based diet and acclimated to the facility for two weeks. At the end of this period, males from each line ( $n=8$ for EW and $n=10$ for DT) were equally assigned to one of two treatment groups and subjected to a short-term $\mathrm{AFB}_{1}$-treatment protocol [21,68]. For the $\mathrm{AFB}_{1}$ treatment, the diet of challenge birds was amended beginning on day 15 with 320 ppb AFB 1 (Sigma-Aldrich, Inc., St. Louis, $\mathrm{MO}, \mathrm{USA}$ ) that continued for 14 days. Control birds continued on the standard diet with $\mathrm{AFB}_{1}$ levels below detection limits ( $<10 \mathrm{ppb}$ ), based on testing of $50 \mathrm{~g}$ of feed extracted and cleaned using Mycosep 112 AflaZON cleanup columns (Romer Labs., Union, MO, USA), and examined by HPLC. Birds were weighed three times per week and feed and water availability checked daily. At the conclusion of the 14 day challenge period, birds were sacrificed by $\mathrm{CO}_{2}$ asphyxiation and blood collected by cardiac puncture for DNA and serological analysis. Livers were removed, examined, weighed, sampled, and fixed in neutral buffered formalin for histological examination. Portions of the liver tissues infused with RNAlater (ThermoFisher Scientific, Waltham, MA, USA) for RNA-Seq analysis. All of the procedures were under the authority and institutional approval of Utah State University's Animal Use and Care Committee. Ethical approval code: 2670, Date of approval: 26 September 2016.

\subsection{RNA Isolation and Sequencing}

Total RNA was isolated from each sample by TRIzol extraction (Ambion, Inc., Foster City, CA), DNase-treated (Turbo DNA-freeTM Kit, Ambion, Inc.), and stored at $-80^{\circ} \mathrm{C}$. Initial RNA concentration and quality was assessed by spectrophotometry (Nanodrop 8000). RNA samples were submitted for library preparation and sequencing at the University of Minnesota Genomics Center (UMGC). Replicate samples were sequenced from each treatment group $(n=4)$. Each sample was quantified by RiboGreen assay (Invitrogen Corp., Carlsbad, CA, USA) and RNA integrity confirmed on a 2100 Bioanalyzer (Aligent Technologies, Santa Clara, CA, USA). Each sample had clear $18 \mathrm{~S}$ and $28 \mathrm{~S}$ peak separation on the electropherograms and an average RNA Integrity Number (RIN) of 6.3. Indexed libraries $(n=16)$ were constructed with $1 \mu \mathrm{g}$ of total RNA/sample with the TruSeq RNA Sample Preparation Kit version 2 (Illumina, Inc., San Diego, CA, USA) and size selected for approximately 200 bp inserts. Libraries were multiplexed, pooled, and sequenced over two lanes on the HiSeq 2000 using v3 chemistry (Illumina, Inc.) to produce 101-bp paired-end reads. Data are deposited in the NCBI Gene Expression Omnibus (GEO) repository as part of SRA BioProject 346253.

\subsection{RNA-seq Data Analyses}

Sequence reads were groomed (Trimmomatic, [69]) and quality checked (FastQC, [70]) prior to read mapping (Bowtie v2.2.4.0) on the turkey genome (UMD 5.0, NCBI Annotation 101). Read counts were normalized in CLC Genomics Workbench (CLCGWB v. 8.0.2, CLC Bio, Aarhus, Denmark) by dividing the total read counts by the group sample sum with the results being expressed as reads per 12.2 M. Hierarchical clustering of samples was performed (based on Euclidean sample 
distances with single linkage) in CLCGWB. Principal component analysis (PCA), Volcano plots, and Venn diagrams were used to visualize expression data and the results of significance testing. Empirical analysis of differential gene expression and ANOVA were performed in CLCGWB on EdgeR-normalized read counts. Pair-wise comparisons between treatment groups were made in CLCGWB following the standard workflow Wald test with multi-comparison $p$-values $<0.05$ being considered as significant (Bonferroni and FDR corrected). In each pair-wise comparison, significant DE genes were used to investigate affected gene pathways using Ingenuity Pathway Analysis (IPA, Ingenuity Systems, Redwood City, CA, USA). Gene enrichment tests were performed using the PANTHER Overrepresentation Test (GO Consortium release 20150430, [38]).

\subsection{Quantitative Real-Time PCR}

To more broadly examine the expression profile response of GSTA3 to dietary AFB 1 , quantitative real-time PCR (qRT-PCR) was performed on both domesticated and wild turkey liver samples. Samples included $\mathrm{AFB}_{1}$-treated and control animals (six per group) from the domesticated Nicholas turkey (DT) and Eastern Wild (EW) experiment, plus $\mathrm{AFB}_{1}$-treated and control animals (six per group) of a parallel experiment that included domesticated Broad Breasted White (BB), and birds of the Rio Grande subspecies (RGW, M. g. intermedia) of wild turkey. Four of the six samples for the DT and EW groups were in common with the RNA-seq study.

Briefly, cDNA was synthesized from DNase-treated liver mRNA (TRIzol extracted) using Invitrogen Super Script IV First-strand synthesis kit (Invitrogen, Carlsbad, CA, USA). Expression analysis of gene-specific amplicons was performed with the iTaq Universal SYBR Green Supermix (BioRad, Hercules, CA, SA) with the CFX96 touch real time detection system (BioRad, Hercules, CA, USA). Primers were designed within Primer3 software (http:/ / www.ncbi.nlm.nih.gov/tools/primerblast) from accessioned genomic DNA sequence (NM_001303157.1) to span an exon/exon junction and at least one intron in the amplicon. RefFinder software was utilized to determine the most stable reference gene. Several normalizing genes were tested for uniformity between treatments and lines and RNA polymerase II subunit D (POLR2D, XM_003208947) was found to have the highest stability value (0.848). Target gene reactions were conducted in triplicate, and POLR2D, no template and gDNA controls were run in duplicate. All of the reactions included a disassociation curve to confirm a single product and to preclude the possibility of dimers amplifying. Expression in each RNA sample was normalized first to the control gene POLR2D. Results were interpreted using the Double Delta Ct Analysis $(\Delta \Delta \mathrm{Ct},[71])$ and a comparative $\mathrm{Ct}$ approach. Expression analysis was performed within the Biorad CFX Maestro software package following the standard $\Delta \Delta \mathrm{Ct}$ workflow.

Supplementary Materials: The following are available online at www.mdpi.com/2072-6651/10/1/42/s1. Figure S1: Hierarchical clustering of samples based on Euclidean distance reiterated relationships shown by PCA. Figure S2: Distribution of genes expressed in turkey liver by treatment group. Figure S3: Differential fold change in DEGs shared by Eastern wild (EW) and domesticated (DT) birds exposed to $\mathrm{AFB}_{1}$ in comparison to controls. Table S1. Mean quality-trimmed RNA-seq read counts for genes with mapped reads in the livers of wild and domesticated turkeys. Table S2. Summary of pairwise differential gene expression analysis of liver transcriptomes. Table S3. Fifty genes showing the greatest differential expression in each pairwise comparison of treatment groups. Table S4. Summary of PANTHER Overrepresentation test of the 3380 differentially expressed genes shared in the $\mathrm{AFB}_{1}$-treated birds as compared to controls. Table S5. Significant differentially expressed genes (FDR $p$-values $<0.05$ and $\mid \log _{2} \mathrm{FCl}>2.0$ ) identified in each pairwise comparison of genetic groups (Eastern wild and domesticated turkey).

Acknowledgments: This project was supported by Agriculture and Food Research Initiative Competitive Grant No. 2013-67015-21241 from the USDA National Institute of Food and Agriculture. This research was also supported in part by the Minnesota and Utah Agricultural Experiment Stations, and approved as Utah Agricultural Experiment Station journal paper number 9060.

Author Contributions: K.M.R. and R.A.C. conceived and designed the experiments; K.M.M. and R.A.C. performed the experiments; J.E.A., K.M.M., and K.M.R. analyzed and interpreted the data; K.M.R. drafted the manuscript; R.A.C., K.M.M., J.E.A., and K.M.R. edited and revised the manuscript.

Conflicts of Interest: The authors declare no conflict of interest. 


\section{Abbreviations}

$\begin{array}{ll}\text { AFB }_{1} & \text { aflatoxin } B_{1} \\ \text { AFBO } & \text { exo-AFB1-8,9-epoxide } \\ \text { BB } & \text { Broad Breasted White } \\ \text { BW } & \text { body weight } \\ \text { Ct } & \text { threshold cycle } \\ \text { CYP } & \text { cytochrome P450 } \\ \text { DE } & \text { differentially expressed } \\ \text { DEG } & \text { differentially expressed gene } \\ \text { DT } & \text { domesticated turkey } \\ \text { EW } & \text { Eastern wild turkey (Meleagris gallopavo silvestris) } \\ \text { FC } & \text { fold change } \\ \text { FDR } & \text { false discovery rate } \\ \text { GO } & \text { gene ontology } \\ \text { GST } & \text { glutathione S-transferase } \\ \text { IPA } & \text { Ingenuity Pathway Analysis } \\ \text { lncRNA } & \text { long non-coding RNA } \\ \text { miRNA } & \text { micro-RNA } \\ \text { ncRNA } & \text { non-coding RNA } \\ \text { PCA } & \text { principal component analysis } \\ \text { qRT-PCR } & \text { quantitative real-time polymerase chain reaction } \\ \text { RGW } & \text { Rio Grande wild turkey (Meleagris gallopavo intermedia) }\end{array}$

\section{References}

1. Council for Agricultural Science and Technology (CAST). Mycotoxins: Risks in Plant, Animal and Human Systems; Council for Agricultural Science and Technology: Ames, IA, USA, 2003.

2. Pons, W.A., Jr.; Goldblatt, L.A. The determination of aflatoxins in cottonseed products. J. Am. Oil Chem. Soc. 1965, 42, 471-475. [CrossRef] [PubMed]

3. Winn, R.T.; Lane, G.T. Aflatoxin production on high moisture corn and sorghum with a limited incubation. J. Dairy Sci. 1978, 61, 762-764. [CrossRef]

4. Hill, R.A.; Blankenship, P.D.; Cole, R.J.; Sanders, T.H. Effects of soil moisture and temperature on preharvest invasion of peanuts by the Aspergillus flavus group and subsequent aflatoxin development. Appl. Environ. Microbiol. 1983, 45, 628-633. [PubMed]

5. Miraglia, M.; Marvin, H.J.; Kleter, G.A.; Battilani, P.; Brera, C.; Coni, E.; Cubadda, F.; Croci, L.; De Santis, B.; Dekkers, S.; et al. Climate Change and Food Safety: An Emerging Issue with Special Focus on Europe. Food Chem. Toxicol. 2009, 47, 1009-1021. [CrossRef] [PubMed]

6. Rawal, S.; Kim, J.E.; Coulombe, R., Jr. Aflatoxin B1 in poultry: Toxicology, metabolism and prevention. Res. Vet. Sci. 2010, 89, 325-331. [CrossRef] [PubMed]

7. Monson, M.S.; Coulombe, R.A.; Reed, K.M. Aflatoxicosis: Lessons from toxicity and responses to aflatoxin B1 in poultry. Agriculture 2015, 5, 742-777. [CrossRef]

8. Rawal, S.; Yip, S.S.; Coulombe, R.A., Jr. Cloning, expression and functional characterization of cytochrome P450 3A37 from turkey liver with high aflatoxin B1 epoxidation activity. Chem. Res. Toxicol. 2010, 23, 1322-1329. [CrossRef] [PubMed]

9. Quist, C.F.; Bounous, D.I.; Kilburn, J.V.; Nettles, V.F.; Wyatt, R.D. The effect of dietary aflatoxin on wild turkey poults. J. Wildl. Dis. 2000, 36, 436-444. [CrossRef] [PubMed]

10. Blount, W.P. Turkey " $X$ " disease. Turkeys 1961, 9, 52-77.

11. Coulombe, R.A., Jr. Biological action of mycotoxins. J. Dairy Sci. 1993, 76, 880-891. [CrossRef]

12. Qureshi, M.A.; Brake, J.; Hamilton, P.B.; Hagler, W.M., Jr.; Nesheim, S. Dietary exposure of broiler breeders to aflatoxin results in immune dysfunction in progeny chicks. Poult. Sci. 1998, 77, 812-819. [CrossRef] [PubMed]

13. Qureshi, M.A.; Heggen, C.L.; Hussain, I. Avian macrophage: effector functions in health and disease. Dev. Comp. Immunol. 2000, 24, 103-119. [CrossRef] 
14. Williams, J.G.; Deschl, U.; Williams, G.M. DNA damage in fetal liver cells of turkey and chicken eggs dosed with aflatoxin B1. Arch. Toxicol. 2011, 85, 1167-1172. [CrossRef] [PubMed]

15. Gross-Steinmeyer, K.; Eaton, D.L. Dietary modulation of the biotransformation and genotoxicity of aflatoxin B(1). Toxicology 2012, 299, 69-79. [CrossRef] [PubMed]

16. Rawal, S.; Coulombe, R.A., Jr. Metabolism of aflatoxin B1 in turkey liver microsomes: The relative roles of cytochromes P450 1A5 and 3A37. Toxicol. Appl. Pharmacol. 2011, 254, 349-354. [CrossRef] [PubMed]

17. Yip, S.S.; Coulombe, R.A., Jr. Molecular cloning and expression of a novel cytochrome P450 from turkey liver with aflatoxin B1 oxidizing activity. Chem. Res. Toxicol. 2006, 19, 30-37. [CrossRef] [PubMed]

18. Ilic, Z.; Crawford, D.; Vakharia, D.; Egner, P.A.; Sell, S. Glutathione-S-transferase A3 knockout mice are sensitive to acute cytotoxic and genotoxic effects of aflatoxin B1. Toxicol. Appl. Pharmacol. 2010, 242, 241-246. [CrossRef] [PubMed]

19. Kim, J.E.; Bunderson, B.R.; Croasdell, A.; Coulombe, R.A., Jr. Functional characterization of alpha-class glutathione s-transferases from the Turkey (Meleagris gallopavo). Toxicol. Sci. 2011, 124, 45-53. [CrossRef] [PubMed]

20. Kim, J.E.; Bunderson, B.R.; Croasdell, A.; Reed, K.M.; Coulombe, R.A., Jr. Alpha-class glutathione S-transferases in wild turkeys (Meleagris gallopavo): Characterization and role in resistance to the carcinogenic mycotoxin aflatoxin B1. PLoS ONE 2013, 8, e60662. [CrossRef] [PubMed]

21. Klein, P.J.; Buckner, R.; Kelly, J.; Coulombe, R.A. Biochemical basis for the extreme sensitivity of turkeys to aflatoxin B1. Toxicol. Appl. Pharmacol. 2000, 165, 45-52. [CrossRef] [PubMed]

22. Klein, P.J.; Van Vleet, T.R.; Hall, J.O.; Coulombe, R.A., Jr. Biochemical factors underlying the age-related sensitivity of turkeys to aflatoxin B1. Comp. Biochem. Physiol. Part C Toxicol. Pharmacol. 2002, 132, 193-201. [CrossRef]

23. Klein, P.J.; Van Vleet, T.R.; Hall, J.O.; Coulombe, R.A., Jr. Dietary butylated hydroxytoluene protects against aflatoxicosis in Turkeys. Toxicol. Appl. Pharmacol. 2002, 182, 11-19. [CrossRef] [PubMed]

24. Eaton, D.L.; Gallagher, E.P. Mechanisms of aflatoxin carcinogenesis. Annu. Rev. Pharmacol. Toxicol. 1994, 34, 135-172. [CrossRef] [PubMed]

25. Guarisco, J.A.; Hall, J.O.; Coulombe, R.A., Jr. Butylated hydroxytoluene chemoprevention of aflatoxicosis-Effects on aflatoxin B1 bioavailability, hepatic DNA adduct formation, and biliary excretion. Food Chem. Toxicol. 2008, 46, 3727-3731. [CrossRef] [PubMed]

26. Monson, M.S.; Settlage, R.E.; McMahon, K.W.; Mendoza, K.M.; Rawal, S.; El-Nemazi, H.S.; Coulombe, R.A., Jr.; Reed, K.M. Response of the hepatic transcriptome to aflatoxin B1 in domestic turkey (Meleagris gallopavo). PLoS ONE 2014, 9, e100930. [CrossRef] [PubMed]

27. Monson, M.S.; Settlage, R.E.; Mendoza, K.M.; Rawal, S.; El-Nezami, H.S.; Coulombe, R.A., Jr.; Reed, K.M. Modulation of the spleen transcriptome in domestic turkey (Meleagris gallopavo) in response to aflatoxin B1 and probiotics. Immunogenetics 2015, 67, 163-178. [CrossRef] [PubMed]

28. Monson, M.S.; Cardona, C.C.; Coulombe, R.A.; Reed, K.M. Hepatic transcriptome responses of domestic and wild turkey embryos to aflatoxin B1. Toxins: Special issue entitled "Aflatoxins". Toxins 2016, 8, 16. [CrossRef] [PubMed]

29. Koishi, R.; Ando, Y.; Ono, M.; Shimamura, M.; Yasumo, H.; Fujiwara, T.; Horikoshi, H.; Furukawa, H. ANGPT13 regulates lipid metabolism in mice. Nat. Genet. 2002, 30, 151-157. [CrossRef] [PubMed]

30. Ono, M.; Shimizugawa, T.; Shimamura, M.; Yoshida, K.; Noji-Sakikawa, C.; Ando, Y.; Koishi, R.; Furukawa, H. Protein region important for regulation of lipid metabolism in angiopoietin-like 3 (ANGPTL3): ANGPTL3 is cleaved and activated in vivo. J. Biol. Chem. 2003, 278, 41804-41809. [CrossRef] [PubMed]

31. Nagasawa, H.; Uto, Y.; Sasaki, H.; Okamura, N.; Murakami, A.; Kubo, S.; Kirk, K.L.; Hori, H. Gc protein (vitamin D-binding protein): Gc genotyping and GcMAF precursor activity. Anticancer Res. 2005, 25, 3689-3695. [PubMed]

32. Geerts, A. History, heterogeneity, developmental biology, and functions of quiescent hepatic stellate cells. Semin. Liver Dis. 2001, 21, 311-335. [CrossRef] [PubMed]

33. Fuchs, A.; Cella, M.; Giurisato, E.; Shaw, A.S.; Colonna, M. Cutting edge: CD96 (tactile) promotes NK cell-target cell adhesion by interacting with the poliovirus receptor (CD155). J. Immunol. 2004, 172, 3994-3998. [CrossRef] [PubMed]

34. Uhlar, C.M.; Whitehead, A.S. Serum amyloid A, the major vertebrate acute-phase reactant. Eur. J. Biochem. 1999, 265, 501-523. [CrossRef] [PubMed] 
35. Michelucci, A.; Cordes, T.; Ghelfi, J.; Pailot, A.; Reiling, N.; Goldmann, O.; Binz, T.; Wegner, A.; Tallam, A.; Rausell, A.; et al. Immune-responsive gene 1 protein links metabolism to immunity by catalyzing itaconic acid production. Proc. Natl. Acad. Sci. USA 2013, 110, 7820-7825. [CrossRef] [PubMed]

36. Gomez, A.; Nekvindova, J.; Travica, S.; Lee, M.Y.; Johansson, I.; Edler, D.; Mkrtchian, S.; Ingelman-Sundberg, M. Colorectal cancer-specific cytochrome P450 2W1: Intracellular localization, glycosylation, and catalytic activity. Mol. Pharmacol. 2010, 78, 1004-1011. [CrossRef] [PubMed]

37. Karlgren, M.; Ingelman-Sundberg, M. Tumour-specific expression of CYP2W1: Its potential as a drug target in cancer therapy. Expert Opin. Ther. Targets 2007, 11, 61-67. [CrossRef] [PubMed]

38. Mi, H.; Huang, X.; Muruganujan, A.; Tang, H.; Mills, C.; Kang, D.; Thomas, P.D. PANTHER version 11: Expanded annotation data from Gene Ontology and Reactome pathways, and data analysis tool enhancements. Nucleic Acids Res. 2017, 45, D183-D189. [CrossRef] [PubMed]

39. Wang, Y.; McNutt, M.C.; Banfi, S.; Levin, M.G.; Holland, W.L.; Gusarova, V.; Gromada, J.; Cohen, J.C.; Hobbs, H.H. Hepatic ANGPTL3 regulates adipose tissue energy homeostasis. Proc. Natl. Acad. Sci. USA 2015, 112, 11630-11635. [CrossRef] [PubMed]

40. Racioppi, L.; Means, A.R. Calcium/calmodulin-dependent kinase IV in immune and inflammatory responses: Novel routes for an ancient traveler. Trends Immunol. 2008, 29, 600-607. [CrossRef] [PubMed]

41. Zhang, Y.; Burke, C.W.; Ryman, K.D.; Klimstra, W.B. Identification and characterization of interferon-induced proteins that inhibit alphavirus replication. J. Virol. 2007, 81, 11246-11255. [CrossRef] [PubMed]

42. Lu, M.Y.; Liao, F. Interferon-stimulated gene ISG12b2 is localized to the inner mitochondrial membrane and mediates virus-induced cell death. Cell Death Differ. 2011, 18, 925-936. [CrossRef] [PubMed]

43. Irgens, H.U.; Fjeld, K.; Johansson, B.B.; Ringdal, M.; Immervoll, H.; Leh, S.; Søvik, O.; Johansson, S.; Molven, A.; Njølstad, P.R. Glycogenin-2 is dispensable for liver glycogen synthesis and glucagon-stimulated glucose release. J. Clin. Endocrinol. Metab. 2015, 100, E767-E775. [CrossRef] [PubMed]

44. Kim, M.A.; Sohn, Y.C. Characterization of a sea urchin IQ Motif Containing Protein D as a coactivator of nuclear receptors. Zool. Sci. 2017, 34, 235-241. [CrossRef] [PubMed]

45. Bedard, L.L.; Massey, T.E. Aflatoxin B1-induced DNA damage and its repair. Cancer Lett. 2006, 241, $174-183$. [CrossRef] [PubMed]

46. Giambrone, J.J.; Diener, U.L.; Davis, N.D.; Panangala, V.S.; Hoerr, F.J. Effect of purified aflatoxin on broiler chickens. Poult. Sci. 1985, 64, 852-858. [CrossRef] [PubMed]

47. Giambrone, J.J.; Diener, U.L.; Davis, N.D.; Panangala, V.S.; Hoerr, F.J. Effects of aflatoxin on young turkeys and broiler chickens. Poult. Sci. 1985, 64, 1678-1684. [CrossRef] [PubMed]

48. Chen, X.; Horn, N.; Applegate, T.J. Efficiency of hydrated sodium calcium aluminosilicate to ameliorate the adverse effects of graded levels of aflatoxin B1 in broiler chicks. Poult. Sci. 2014, 93, 2037-2047. [CrossRef] [PubMed]

49. Huff, W.E.; Kubena, L.F.; Harvey, R.B.; Corrier, D.E.; Mollenhauer, H.H. Progression of aflatoxicosis in broiler chickens. Poult. Sci. 1986, 65, 1891-1899. [CrossRef] [PubMed]

50. Yarru, L.P.; Settivari, R.S.; Antoniou, E.; Ledoux, D.R.; Rottinghaus, G.E. Toxicological and gene expression analysis of the impact of aflatoxin B1 on hepatic function of male broiler chicks. Poult. Sci. 2009, 88, 360-371. [PubMed]

51. Zhang, N.Y.; Qi, M.; Gao, X.; Zhao, L.; Liu, J.; Gu, C.Q.; Song, W.J.; Krumm, C.S.; Sun, L.H.; Qi, D.S. Response of the hepatic transcriptome to aflatoxin B1 in ducklings. Toxicon 2016, 111, 69-76. [CrossRef] [PubMed]

52. Wu, Z.L.; Sohl, C.D.; Shimada, T.; Guengerich, F.P. Recombinant enzymes overexpressed in bacteria show broad catalytic specificity of human cytochrome P450 2W1 and limited activity of human cytochrome P450 2S1. Mol. Pharmacol. 2006, 69, 2007-2014. [CrossRef] [PubMed]

53. Yang, Y.H.; Miranda, C.L.; Henderson, M.C.; Wang-Buhler, J.L.; Buhler, D.R. Heterologous expression of CYP2K1 and identification of the expressed protein (BV-CYP2K1) as lauric acid (omega-1)-hydroxylase and aflatoxin B1 exo-epoxidase. Drug Metab. Dispos. 2000, 28, 1279-1283. [PubMed]

54. Laborde, E. Glutathione transferases as mediators of signaling pathways involved in cell proliferation and cell death. Cell Death Differ. 2010, 17, 1373-1380. [CrossRef] [PubMed]

55. Chen, J.; Chen, K.; Yuan, S.; Peng, X.; Fang, J.; Wang, F.; Cui, H.; Chen, Z.; Yuan, J.; Geng, Y. Effects of aflatoxin B1 on oxidative stress markers and apoptosis of spleens in broilers. Toxicol. Ind. Health 2016, 32, 278-284. [CrossRef] [PubMed] 
56. Eraslan, G.; Akdogan, M.; Yarsan, E.; Sahindokuyucu, F.; Essiz, D.; Altintas, L. The effects of aflatoxins on oxidative stress in broiler chickens. Turk. J. Vet. Anim. Sci. 2005, 29, 701-707.

57. Yang, W.; Lian, J.; Feng, Y.; Srinivas, S.; Guo, Z.; Zhong, H.; Zhuang, Z.; Wang, S. Genome-wide miRNA-profiling of aflatoxin B1-induced hepatic injury using deep sequencing. Toxicol. Lett. 2016, 226, 140-149. [CrossRef] [PubMed]

58. Livingstone, M.C.; Johnson, N.M.; Roebuck, B.D.; Kensler, T.W.; Groopman, J.D. Profound changes in miRNA expression during cancer initiation by aflatoxin $\mathrm{B}_{1}$ and their abrogation by the chemopreventive triterpenoid CDDO-Im. Mol. Carcinog. 2017, 56, 2382-2390. [CrossRef] [PubMed]

59. Merrick, B.A.; Phadke, D.P.; Auerbach, S.S.; Mav, D.; Stiegelmeyer, S.M.; Shah, R.R.; Tice, R.R. RNA-Seq profiling reveals novel hepatic gene expression pattern in aflatoxin B1 treated rats. PLoS ONE 2013, 8, e61768. [CrossRef] [PubMed]

60. Shi, J.; He, J.; Lin, J.; Sun, X.; Sun, F.; Ou, C.; Jiang, C. Distinct response of the hepatic transcriptome to Aflatoxin B1 induced hepatocellular carcinogenesis and resistance in rats. Sci. Rep. 2016, 6, 31898. [CrossRef] [PubMed]

61. Bourd-Boittin, K.; Bonnier, D.; Leyme, A.; Mari, B.; Tuffery, P.; Samson, M.; Ezan, F.; Baffet, G.; Theret, N. Protease profiling of liver fibrosis reveals the ADAM metallopeptidase with thrombospondin type 1 motif, 1 as a central activator of transforming growth factor beta. Hepatology 2011, 54, 2173-2184. [CrossRef] [PubMed]

62. Giambrone, J.J.; Diener, U.L.; Davis, N.D.; Panangala, V.S.; Hoerr, F.J. Effects of purified aflatoxin on turkeys. Poult. Sci. 1985, 64, 859-865. [CrossRef] [PubMed]

63. Sharma, R.P. Immunotoxicity of mycotoxins. J. Dairy Sci. 1993, 76, 892-897. [CrossRef]

64. Bababunmi, E.A.; Bassir, O. A delay in blood clotting of chickens and ducks induced by aflatoxin treatment. Poult. Sci. 1982, 61, 166-168. [CrossRef] [PubMed]

65. Doerr, J.A.; Hamilton, P.B. Aflatoxicosis and intrinsic coagulation function in broiler chickens. Poult. Sci. 1981, 60, 1406-1411. [CrossRef] [PubMed]

66. Witlock, D.R.; Wyatt, R.D. Effect of dietary aflatoxin on hemostasis of young turkey poults. Poult. Sci. 1981, 60, 528-531. [CrossRef] [PubMed]

67. Granevitze, Z.; Blum, S.; Cheng, H.; Vignal, A.; Morisson, M.; Ben-Ari, G.; David, L.; Feldman, M.W.; Weigend, S.; Hillel, J. Female-specific DNA sequences in the chicken genome. J. Hered. 2007, 98, 238-242. [CrossRef] [PubMed]

68. Coulombe, R.A.; Guarisco, J.A.; Klein, P.J.; Hall, J.O. Chemoprevention of aflatoxicosis in poultry by dietary butylated hydroxytoluene. Anim. Feed Sci. Technol. 2005, 121, 217-225. [CrossRef]

69. Bolger, A.M.; Lohse, M.; Usadel, B. Trimmomatic: A flexible trimmer for Illumina sequence data. Bioinformatics 2014, 30, 2114-2120. [CrossRef] [PubMed]

70. Andrews, S. FastQC: A Quality Control Tool for High Throughput Sequence Data. 2010. Available online: http:/ / www.bioinformatics.babraham.ac.uk/projects/fastqc/ (accessed on 10 January 2018).

71. Schmittgen, T.D.; Livak, K.J. Analyzing real-time PCR data by the comparative C(T) method. Nat. Protoc. 2008, 3, 1101-1108. [CrossRef] [PubMed]

(c) 2018 by the authors. Licensee MDPI, Basel, Switzerland. This article is an open access article distributed under the terms and conditions of the Creative Commons Attribution (CC BY) license (http://creativecommons.org/licenses/by/4.0/). 